\title{
Down-regulated MicroRNAs in Gastric Carcinoma May Be Targets for Therapeutic Intervention and Replacement Therapy
}

\author{
ULRICH H. WEIDLE ${ }^{1}$, FABIAN BIRZELE ${ }^{2}$, SIMON AUSLAENDER ${ }^{1}$ and ULRICH BRINKMANN ${ }^{1}$ \\ ${ }^{1}$ Large Molecule Research, Roche Pharma Research and Early Development (pRED), \\ Roche Innovation Center Munich, Penzberg, Germany; \\ ${ }^{2}$ Pharmaceutical Sciences, Roche Pharma Research and Early Development (pRED), \\ Roche Innovation Center Basel, Basel, Switzerland
}

\begin{abstract}
Gastric cancer is one of the leading types of cancer with an annual death toll of 700,000 worldwide. Despite the fact that several agents are approved for its treatment, high percentage of recurrence and intractability of metastatic disease remain a major problem. The identification of new targets and modalities for treatment are therefore of high priority. We have searched the literature for microRNAs down-regulated in gastric cancer with efficacy in gastric cancer-related murine xenograft models after reconstitution therapy. Among the identified miRs were 25 miRs targeting transcription factors, seven of them regulating cell-cycle and apotosis-related targets, and five of them regulating GTPase-related targets such as GAPs and GEFs. According to criteria such as prognostic impact, functional data, and tractability, miR-133 b/a (MCL1) and miR-518 (MDM2) are suggested as potentially valuable targets for further evaluation and possible treatment of gastric cancer.
\end{abstract}

Gastric cancer (GC) is the third-leading cause of cancer worldwide and is the fourth most common cancer with an annual worldwide death toll of 700,000 (1). Stomach tumor types include esophageal gastric cancer, gastrointestinal stromal tumors (GIST) and gastric cancer (GC) (1). In this review we focus on gastric cancer (GC). From a histopathological point of view intestinal and diffuse subtypes

Correspondence to: Ulrich Brinkmann and Ulrich H. Weidle, Roche Innovation Center Munich, Nonnenwald 2, D-82372 Penzberg, Germany. Tel: +4988566013901, e-mail: ulrich.brinkmann@ roche.com (UB); e-mail: weidle49@t-online.de (UHW)

Key Words: Cell-cycle/apoptosis, functional characteristics of targets, prognosis, small GTPases-related and -associated molecules, target validation, tractability, transcription factors, review. of GC have been identified. The first is characterised by well differentiated tubular and glandular structures, and the second by undifferentiated or poorly differentiated cells and lack of gland formation (1). From a molecular point of view the following subtypes have been characterized: Epstein-BarrVirus (EBV), microsatellite instability (MSI), genomically stable (GS) and chromosomal instability (CIN) subtypes, all correlated with differential prognosis (2). The standard therapy of GC patients is platinium- and fluoropyrmidinebased chemoradiotherapy or patient subgroup-specific therapy with Herceptin and chemotherapy or the vascular-endothelial growth factor receptor 2 (VEGFR2) monocolonal antibody $(\mathrm{mAb})$ Ramucirumab in combination with other agents $(3,4)$. Several Phase III studies are ongoing with immune checkpoint-related mAbs directed against cytotoxic Tlymphocyte associated protein 4 (CTLA4), programmed death 1 (PD1) and programmed death-ligand 1 PD-L1 $(3,4)$. So far, surgery is the only potentially curative therapy, yet still more than half of radically resected GC patients relapse locally or develop distant metastasis $(3,4)$. Preferential organs of metastasis are the liver (48\%), peritoneum (32\%), lung (15\%) and bone (12\%) (5). Relapsed and metastatic GC only poorly respond to established treatment regimens $(3,4)$. Regarding the molecular genetics of GC, mutations or loss of heterozygosity of adenomatous-polyposis-coli (APC) (6), chromatin-remodelling protein AT-rich interactive domain containing protein 1A (ARID1A) $(7,8)$, cell adhesion protein E-cadherin (9) and Ras homolog family member A (RHOA) involved in regulation of the cytoskeleton have been identified $(10,11)$. Altogether, the identification of new targets and treatment modalities for GC is highly desired. In this review, we describe the role of miRs that are downregulated in GC, representing tumor-suppressive microRNAs (miRs) affecting transcription factors, cell-cycle related and anti-apoptotic proteins as well as miRs that affect small GTPases and their interacting proteins and proteins such as 
guanine nucleotide exchange factors (GEFs) and GTPases activating proteins (GAPs), in pathogenesis and metastasis of GC. We focus on miRs which are down-regulated in GC tissue in comparison to corresponding normal tissues and exhibit efficacy in preclinical in vivo models.

\section{Roles of microRNAs in Oncology}

microRNAs (miRs) are double-stranded RNAs comprising 22$25 \mathrm{nts}$ and are generated from hairpin-containing precursor transcripts (12). They are transcribed in the nucleus by RNA polymerase II, processed, exported to the cytoplasm and released as $22-25 \mathrm{nts}$ miR-duplexes $(13,14)$. One of the strands of the RNA duplex is maintained (guide strand), the other strand (passenger strand) is degraded $(13,14)$. Subsequently, the guide strand binds to the 3'-untranslated region (3'-UTR) of the mRNA of the corresponding targets and mediates their degradation and/or inhibition of their translation $(13,14)$. In contrast to interfering RNA (RNAi) which targets a single type of mRNA, miRs can affect up to several hundreds of different mRNAs (15). Therefore, miRs can modulate several oncogenic and tumor-suppressive pathways and hence have the potential of rewiring tumor cells to a differentiated state (15). In humans, approximately 1,000 genes encoding miRs have been identified so far (16). They are positioned as separate or clustered genes, in introns or in coding regions (6). miRs can act as oncogenes as well as tumor suppressors (16). Their actual function can be context-dependent (16).

In a proof-of-concept experiment (POC) it was shown that expression of the miR-15/16 cluster in mice prevents chronic lymphocytic leukemia analogous to the human disease by targeting B cell lymphoma 2 (BCL2) (17). In another POC experiment an oncogenic role was identified for miR-221, which induced hepatocellular carcinoma in transgenic mice after liver-specific expression (18). miRs play a role in tumorigenesis, angiogenesis, tumor-stromal interactions, and metastasis (19). We have recently summarized their role in metastasis in breast, prostate, ovarian, lung, pancreatic and liver cancer (20-25).

\section{miRs Targeting Transcription Factors}

miR-15a-3p and miR-16-1-3p target TWIST-1. Overexpression of miRs $-15 a-3 p$ and $-16-1-3 p$ (Figure 1A) in BGC-823 GC cells suppresses migration, invasion and colony formation in vitro (26). Twist family basic helix-loophelix (BHLH) transcription factor 1 (TWIST-1), which is involved in the epithelial mesenchymal transition (EMT) process by up-regulation of $\mathrm{N}$-Cadherin and down-regulation of E-Cadherin and is over-expressed in GC, has been shown to be a direct target of both miRs (26-28). TWIST- 1 overexpression induced cell migration and invasion (26). Both miRs suppress tumorigenicity in nude mice, whereas over- expression of TWIST-1 reverses miR-mediated inhibition of tumorigenesis (26). In GC clinical samples, an inverse correlation between expression of miR-15a-3p, miR-16-1-3p and TWIST-1 mRNA and protein has been been noted.

miR-141 and -200a,b,c target ZEB1,2. miRs -141 and -200c (Figure 1A) reduce invasion ability of the metastatic GC cell line 58As9 (29). In nude mice, synthetic mimics for miR-141 and $-200 \mathrm{c}$ complexed with atelocallagen inhibit peritoneal dissemination to the omentum of orthotopically implanted 58As9 cells (29). miR-141 targets the transcription factor zinc finger E-box binding homeobox 2 (ZEB2), whereas miR-200c directly targets zinc finger E-box binding homeobox 1 (ZEB1) (29). Over-expression of miR-200a in SGC-7901 GC cells inhibits cell growth and invasion and induces G0/G1 phase arrest in vitro $(30,31)$. Transfection of miR-200a into SGC-7901 cells inhibits tumor gowth (TG) in vivo in nude mice by up-regulation of E-cadherin and inhibition of WNT/ $\beta$-catenin signaling $(30,31)$. miR-200a inhibits EMT and targets ZEB1 and ZEB2 $(30,31)$. miR200b over-expression in the GC cell lines MGC-803 and SGC-7901 induces an epithelial phenotype and suppresses TG in nude mice (32). miR-200b suppresses N-Cadherin, vimentin and ZEB1 and induces E-Cadherin in vivo (32). ZEB1 and ZEB2 are inducers of EMT and metastasis (33, 34). In GC patients, ZEB1 and ZEB2 expression is associated with poor survival (35).

miRs -105, -138 target SOX9 and SOX4. miRs-105 and -138 (Figure 1A) target sex determining region Y-related high mobility group 9 and 4 (SOX9 and SOX4) (36-38). Reduced levels of miR-105 and/or increased SOX9 expression are associated with poor survival in GC patients (36-38). miR-138 is reduced in GC patients with lymph node metastasis in comparison to patients without lymph node metastasis (38). miR-105 and -138 suppress proliferation, colony formation, migration, invasion and EMT of BGC-823 and SGC-7901 GC cells (36-38). Ectopically expressed miR-105 inhibits TG of SGC-7901 cells subcutaneously implanted into nude mice and their metastasis to the lungs $(36,37)$. miR-138 transfected SGC-7901 cells show decreased TG in nude mice after subcutaneous implantation (38). SOX proteins are transcription factors of a gene family of 20 members in humans, which bind to the minor groove of DNA by their high motility group (HMG) domain. They have a regulatory function in development, cell-fate decision, sex determination and differentiation $(39,40)$. Their deregulation leads to cancer initiation, progression and metastasis, angiogenesis and lymphatic angiogenesis and changes in the tumor microenvironment $(39,40)$. SOX4 expression has been associated with an unfavorable prognosis in GC patients (41). Expression of SOX9 correlates with poor clinical outcome in the MSS/TP53+ subgroup of GC patients (42). 

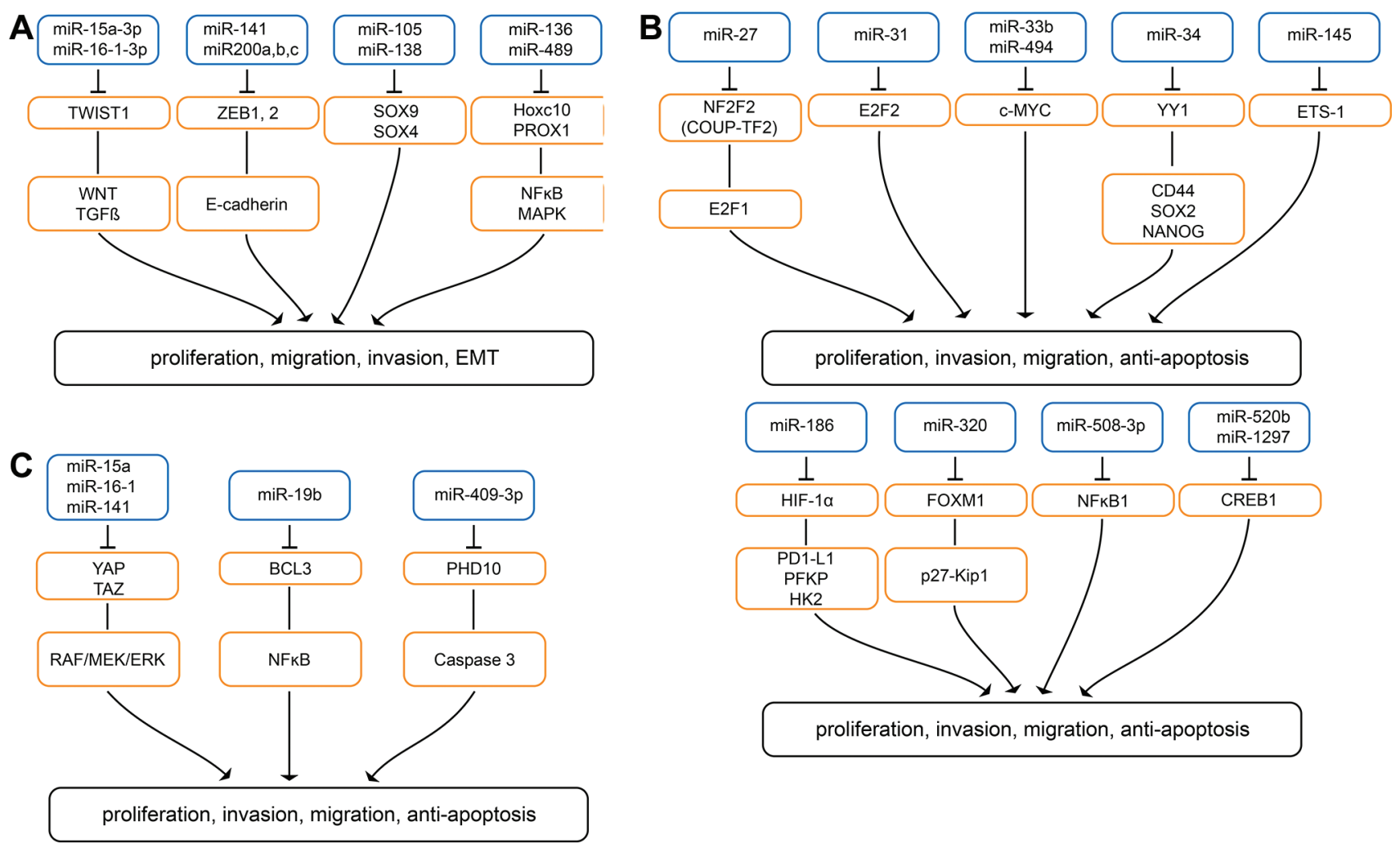

Figure 1. Tumor-suppressive miRs targeting transcription factors and coactivators with activity in preclinical in vivo models. A: miRs targeting transcription factors: miRs-15a-3p, -16-1-3p, -141, -200c, -105, -138, -136, -489. HOXC10: Homeobox transcription factor C10; MAPK: mitogen activated protein kinase; $N F K B$ : nuclear factor $K B$; PROX1: prospero homeobox protein 1; SOX 4,9: SRY-related HMG-box 4,9; TGF $\beta$ : transforming growth factor $\beta$; TWIST1: transcription factor TWIST1; WNT: WNT signaling; ZEB1,2: zinc finger E-box binding homeobox 1,2. B: miRs targeting further transcription factors: miRs- 27, -31, miR-33b, -494, -34, -145, -186, -320, -508-3p, -520b, -1297. c-MYC: Transcription factor c-MYC; COUP-TF2: chicken ovalbumin upstream promoter; CREB1: cAMP response element binding protein 1; E2F2: transcription factor E2F2; ETS1: E26 transformation specific-1; FOXM1: forkhead protein M1; HIF-1 $\alpha$ : hypoxia-inducible factor 1; NFkB1: nuclear factor kB1; NR2F2: nuclear receptor 2 subfamily 2; HK2: hexokinase 2; PD-1L: programmed cell death ligand 1; PFKP: platelet isoform phosphofructokinase; p27-Kip1: cyclin-dependent kinase inhibitor 1; YY1: Ying and Yang 1. C: miRs targeting transcriptional co-activators: miRs- 15a, -16-1, -141, -19b, -409-3p. BCL3: B-cell lymphoma 3; ERK: extracellular signal-regulated kinase; MEK: mitogen-activated protein kinase kinase, $N F \kappa B$ : nuclear factor $к B$; PHD10: PHD finger protein 10; TAZ: transcriptional co-activator with PDZ-binding motif; YAP: yes activated protein.

miRs-136 and -489 target homeobox genes HOXC10 and $P R O X-1$. miR-136 (Figure 1A) is down-regulated in GC peritoneal metastasis tissue and is associated with worse prognosis (43). GC-9811P GC cells expressing exogenous miR-136 display unaltered proliferation or apoptotic rates but show reduced mobility and invasion. In vivo, a decrease in peritoneal metastasis formation was noted in a murine tumor model (43). Homebox protein HOXC10 was identified as a direct target of miR-136 (43). Knockdown of HOXC10 reduces migration and invasion of GC-9811P cells in vitro and abolishes metastasis in peritoneal colonization assays (43).

HOXC10 is a member of the human HOX gene family comprising 39 genes, which contain a homeobox gene sequence in the range of $180 \mathrm{bp}$ with DNA binding capacity of the corresponding protein moiety (44). Homeobox genes and their proteins regulate patterns of anatomical development in animals and humans. HOXC10 promotes cell proliferation and migration of GC cells through nuclear factor kappaB (NFkB), mitogen-activated protein kinase (MAPK) pathways and up-regulation of pro-inflammatory cytokines such as tumor necrosis factor $\alpha$ and $\beta$ (TNF $\alpha, \beta)$, interleukin 6 (IL6) and epidermal growth factor (EGF) (4548). miR-489 (Figure 1A) expression is reduced in GC tissues in comparison to corresponding normal tissues (49). miR-489 inhibits proliferation of AGS GC cells and tumorigenicity of AGS cells in nude mice after subcutaneous implantation (49). Prospero homeobox protein 1 (PROX-1) was identified as a direct target of miR-489 (49). Expression of PROX-1 is associated with progression and prognosis in GC (49). PROX-1 is a mediator of tumor cell proliferation, 
angiogenesis and lymphangiogenesis and has been identified as a marker for lymphocytic endothelium $(50,51)$.

miR-27b targets NR2F2. miR-27b (Figure 1B) inhibits proliferation, migration, and invasion of MGC-803 GC cells (52). TG and metastasis to the liver of MGC-803 cells expressing exogenous miR-27b are inhibited after implantation into the stomach or the spleen of nude mice (52). Nuclear receptor subfamily 2, group F, member 2 (NR2F2), also referred to as chicken ovalbumin upstream promoter transcription factor-II (COUP-II) has been identified as a direct target of miR-27b (52). NR2F2 is an orphan nuclear receptor with a DNA and ligand binding domain and context-dependent onogenic and tumor suppressive functions $(53,54)$. NR2F2 has crucial functions in cell differentiation and cell metabolism $(53,54)$. In GC, NR2F2 has been found to activate embryonic pathways through up-regulation of expression of Cadherins 6 to 11 (55). However, in GC also a tumor-suppressive function has been reported for NR2F2 through inhibition of proliferation, invasion, and metastasis (56).

miR-31 targets E2F2. miR-31 (Figure 1B) is down-regulated in $\mathrm{GC}$ and GC-derived cell lines in comparison to adjacent normal tissues and GES-1 cells (57). miR-31 over-expression in SGC-7901 and MGC-803 cells leads to cell-cycle arrest in the G1 phase, increase in apoptotic index and inhibition of migration and invasion (57). miR-31-mimic transduced SGC-7901 cells exhibit decreased TG after subcutaneous implantation into nude mice and decreased liver metastasis after tail vein injection (57). Transcription factor E2F2 has been identified as a direct target of miR-31 (57). Knockdown of E2F2 reduces cell migration and invasion of SGC7901 and MGC-803 cells (57). E2F2 binds to retinoblastoma protein $(\mathrm{Rb})$ and after its dissociation it can act as a transcriptional activator or repressor (58). However, the data for the role of E2F2 in GC cancer are controversial since increased expression of E2F2 also was associated with a favorable prognosis (59).

miRs-33b and -494 target c-MYC. miR-33b (Figure 1B) is down-regulated due to DNA methylation in GC samples in comparison to adjacent normal tissues. Its decrease correlates with disease progression and GC patients with metastases have lower levels of miR-33b than those without metastases (60). Over-expression of miR-33b inhibits proliferation, migration, and invasion of the GC cell lines MGC-803 and HGC-27 (60). Tumorigenicity of subcutaneously implanted HGC-27 cells in nude mice is suppressed following their transduction with miR-33b (60). The transcription factor cMYC was identified as a target of miR-33b (60). miR-494 (Figure 1B) is down-regulated in GC samples and cell lines and is negatively correlated with survival (61). GC-derived
AGS cells that are transfected with miR-494 exhibit delayed G1/S entry (61). c-MYC was identified as a direct target of miR-494 (61). Tumor burden of subcutaneously implanted AGS cells into nude mice was attenuated by intraperitoneal injection of a miR-494 mimic (61). c-MYC is a transcription factor with basic helix-loop-helix and leucine zipper structural motifs, which activates many proliferative genes (62). In addition, c-MYC has an impact on cell growth, ribosomal RNA processing and other crucial physiological processes (6366). c-MYC has been found to be deregulated in GC (67).

miR-34 targets YY1. Ying and Yang1 (YY1), a member of the GLI-Kruppel class of zinc finger transcription factors, was identifed as the target of miR-34 (Figure 1B) family, which consists of miRs-34a, -b and -c (68). YY1 contributes to tumor sphere formation in GC-derived SC-M1 cells and up-regulates pluripotency genes cluster of differentiation 44 (CD44), octamer-binding transcription factor 4 (OCT4), SOX2 and homeobox protein NANOG. It is also involved in maintainance of the cancer stem cell (CSC) phenotype (68). Knock-down of YY1 in SC-M1 cells leads to expression of epithelial markers E-Cadherin and plakoglobin (a catenin protein family member homologous to $\beta$-catenin), and to decrease of mesenchymal markers $\mathrm{N}$-Cadherin and vimentin (68). Transfection of SC-M1 cells with miR-34b and 34c inhibits tumor growth after subcutaneous implantation and lung metastases after tail vein injection in nude mice (68). miR-34a inhibitors expressed in SC-M1 cells lead to increased lung metastasis in the experimental metastasis assay system in nude mice (68). YY1 activates and represses many genes involved in cellular differentiation, DNA repair, cell division, survival, apoptosis, and autophagy with a context-dependent function as a tumor driver or suppressor (69, 70). YY1 expression contributes to gastric carcinogenesis and its nuclear expression correlates with survival in patients with early-stage gastric adenocarcinoma (71). YY1 also is involved in the regulation of cancer immune cell resistance by up-regulating PD-L1 (72).

miR-145 targets ETS-1. Transcription factor E26 transformation specific-1 (ETS-1) has been identified as a target of miR-145 (Figure 1B) (73). ETS-1 is the cellular homolog of the v-ETS oncogene, and is highly expressed in GC tissues and cell lines. Its expression inversely correlates with miR-145 levels (73). In SGC-7901 and MKN-45 GC cell lines, ectopic expression of miR-145 has no influence on proliferation, but inhibits migration, invasion, and tube formation (73). Transfection of ETS-1 restored the decrease in migration, invasion, and angiogenesis in SGC-7901 and MKN45 cells mediated by miR-145 (73), whereas knockdown of miR-145 promoted migration, invasion, and angiogenesis (73). Knockdown of ETS-1 phenocopies the effects of miR-145 over-expression in GC cells in vitro (73). Transfection of SGC- 
7901 cells with miR-145 has no influence on TG in vivo, but decreases lung metastasis after tail vein injection (73). The ETS family of transcription factors is composed of 28 members in humans and regulates genes involved in extracellular matrix (ECM) remodelling, migration, and invasion (74). ETS-1 induces genes such as matrix metalloproteinases 1 and 9 (MMP-1, -9) and urokinase plasminogen activator (uPA) (75) and is involved in EMT and angiogenesis (76). GC patients with tumors that express ETS-1 have poorer prognosis than those without expression of ETS-1 (77).

miR-186 targets HIF-1 $\alpha$. miR-186 (Figure 1B) is downregulated in GC (78). In MKN45 and SGC-7901 cells, miR186 inhibits cell migration and proliferation and promotes apoptosis (78). Hypoxia-inducible factor- $1 \alpha$ (HIF-1 $\alpha$ ) was identified as a direct target of miR-186 (78). miR-186 promotes down-regulation of hexokinase 2 (HK2) and platelet-type phosphofructokinase (PFKP), two enzymes involved in glycolysis (78). In vivo studies in nude mice with MKN45 and SGC-7901 cells support a tumor-suppressive role of miR-186 (78). Strongest growth inhibition was achieved by combination of miR-186 mimics and small hairpin (sh) HIF$1 \alpha$ (78). In GC, HIF- $1 \alpha$ has an impact on apoptosis, EMT, and drug resistance $(79,80)$. HIF-1 $\alpha$ expression indicates a poor prognosis in $\mathrm{GC}$ patients $(81,82)$.

miR-320 targets FOXM1. Human GC exhibits low expression of miR-320 (Figure 1B) (83). Forkhead box protein M1 (FOXM1) was identified as a target of miR-320 (83). Over-expression of miR-320 in the GC cell lines AGS, BGC-823 and HGC-27 leads to inhibition of FOXM1 expression and up-regulation of cyclin-dependent kinase inhibitor 1B (p27KIP1) (83). Conversely, suppression of miR-320 in BGC-823 GC cells leads to increased TG in nude mice through altered FOXM1-p27KIP1 signaling (83). FOXM1 is frequently over-expressed in various cancers, functions as a proto-oncogene and plays a role in cell-cycle progression $(84,85)$. In GC, FOXM1 facilitates cell migration by inducing cathepsin (86) and cooperates with urokinase plasminogen activator (uPA) to promote disease progression (87). Expression of FOXM1 is associated with poor survival in patients with GC (88).

miR-508-3p targets $N F k B 1$. NFkB1 (p50) and RelA (p65) are up-regulated in primary GC tumors as well as in GC-derived cell lines (89). NFkB1 has been identified as a direct target of miR-508-3p in GC (89). NFKB1 and transcription factor p65 (RELA) mediate proliferation, invasion, and colony formation of MKN28, MGC-803 and SGC-7901 GC cells (89). NFkB1 expression shows a negative correlation with miR-508-3p (Figure 1B) expression in GC specimens (89). NFkB1 expression counteracts the tumor-suppressive effect of miR-508-3p (89). In vivo, MGC-803 cells treated with small interfering RNA (si) NFkB1 grow slower than the untreated cell line after subcutaneous implantation into nude mice (89). In GC, NFkB1 induces cytokines/chemokines, growth factors, anti-apoptotic factors, regulators of angiogenesis and metalloproteinases (90). Furthermore, it has been shown that signal transducer and activator of transcription (STAT3) and NFkB cooperate to promote progression of GC (91).

miR-520b, -1297 target CREB1. miR-520b (Figure 1B) inhibits migration and invasion of GC cells BGC-823 and MKN45 (92). Expression of miR-520b is dependent on zinc transcription factor GATA-binding factor 6 (GATA6) (93), which in turn is down-regulated in metastatic GC specimens and GC-derived cell lines (92). Down-regulation of GATA6 correlates with poor prognosis in GC (92). cAMP response element binding protein 1 (CREB1) has been identified as a direct target of miR-520b. Ectopic expression of miR-520b inhibits migration and invasion of GC cell lines BGC-823 and MKN45 in vitro and in vivo in nude mice (93). miR-1297 (Figure 1B) also targets CREB1 and shows significantly lower expression in GC tissue samples compared to adjacent normal tissue (94). Lower expression of miR-1297 correlates with larger tumor size, lymph node metastases, advanced tumor/lymph node/metastasis (TNM) type and poor survival of GC patients (94). Conversely, upregulation of miR-1297 leads to inhibition of proliferation and colony formation in vitro in GC cell lines and to suppression of TG in nude mice after subcutaneous implantation (94). Increased CREB1 expression rescued the in vitro effects of miR-1297 in GC cell lines. Independently, it has been shown that CREB1 promotes GC cell proliferation, colony formation, invasion and migration, and TG in vivo (95). CREB1 knockdown in GC cells leads to inhibition of cyclin D1 (CCND1), BCL2 and MMP9 (95). High expression of CREB1 is associated with increased tumor stage, metastasis, and poor outcome in GC patients (96).

\section{Co-activators}

miRs-15a, 16-1, -141 target YAP and TAZ. miR-15a and -16-1 (Figure 1C) are down-regulated in GC. In the cell lines AGS, MKN1 and MGC-803, ectopic expression of miRs-15a and 16-1 inhibits proliferation, migration as well as invasion, and induces G0/G1 cell-cycle arrest (97). Yes-associated protein 1 (YAP1) was identifed as a direct target of miRs -15a and -16-1 (97). YAP1 re-expression abolishes in part the in vitro effects of miRs-15a and -16-1 (97). YAP1 activates the rapidly accelerated fibrosarcoma (RAF)/dual specificity mitogenactivated kinase kinase (MEK)/extracellular regulated kinase (ERK) pathway in GC cells (97). Reduced tumor sizes (vs. controls) were observed after transplantation of siYAP1 expressing MGC-903 cells in nude mice (97). miR-141 (Figure 1C) is down-regulated in primary GC-specimens and correlates 
inversely with metastatic propensity of GC (98). miR-141 inhibits proliferation, invasion, and migration of GC cell lines BGC-823, HGC-27 and SGC-7901 by targeting transcriptional co-activator with PDZ-binding motif (TAZ) (98). HGC-27 GC cells transfected with a miR-141mimic show reduced TG after subcutaneous implantation into nude mice and decreased lung metastases after tail vein injection (98). YAP1 and its paralogue TAZ exert oncogenic activities after association with TEAdomain family (TEAD) transcription factors $(99,100)$. YAP1 and TAZ are repressed by Hippo pathway upstream regulators and are drivers of TG, metastasis, and resistance to therapy (101). It has been shown that YAP/TAZ initiates gastric tumorigenesis by c-MYC (102), and increased expression of TAZ is associated with EMT (103). Expression of TAZ in association with WNT pathway mutations impacts survival outcomes in advanced GC patients treated with first-line chemotherapy (104). YAP1 expression correlates with poor prognosis in GC patients (105).

miR-19b targets BCL3. miR-19b (Figure 1C) is downregulated in GC tissues and cell lines and is associated with clinico-pathological factors and poor prognosis in patients (106). miR-19b inhibits cell proliferation and cell-cycle progression of GC cell lines MGC-803 and SGC-7901 (106). B-cell lymphoma 3 (BCL3) was identified as the target of miR-19b (106). Over-expression of miR-19b inhibits TG of MGC-803 GC cells subcutaneously implanted in nude mice (106). Also, silencing of BCL3 abolishes the effects of miR$19 \mathrm{~b}$ inhibition on cell proliferation and cell-cycle progression (106). BCL3 acts as an oncogene in haematologic malignancies such as B-cell chronic lymphocytic leukemias. But it is also deregulated in solid tumors, modulating proliferation and cell death (107). BCL3 regulates transcription by forming complexes with p50 or p52 homodimers of the NFkB signaling pathway, and also by association with other transcription factors (108). However, the role of BCL3 in GC remains to be explored in more detail.

miR-409-3p targets PHD10. miR-409-3p (Figure 1C) is down-regulated in GC cell lines and tumors (109). In SGC7901 cells, over-expression of miR-409-3p suppresses proliferation and induces apoptosis in vitro and in vivo in nude mice (109). PHD finger protein 10 (PHD10) was identified as a target of miR-409-3p (109). Expression of the human PHD10 (plant homeodomain containing gene 10) is required for cell proliferation in normal and SV40 immortalized human fibroblasts (110). In GC, PHD10 exerts an anti-apoptotic function by suppressing caspase 3 (111).

\section{Cell-cycle and Apoptosis}

miR-29c targets CCND2. miR-29 (Figure 2) is a family consisting of three members (29a-, b- and c) with miR-29c

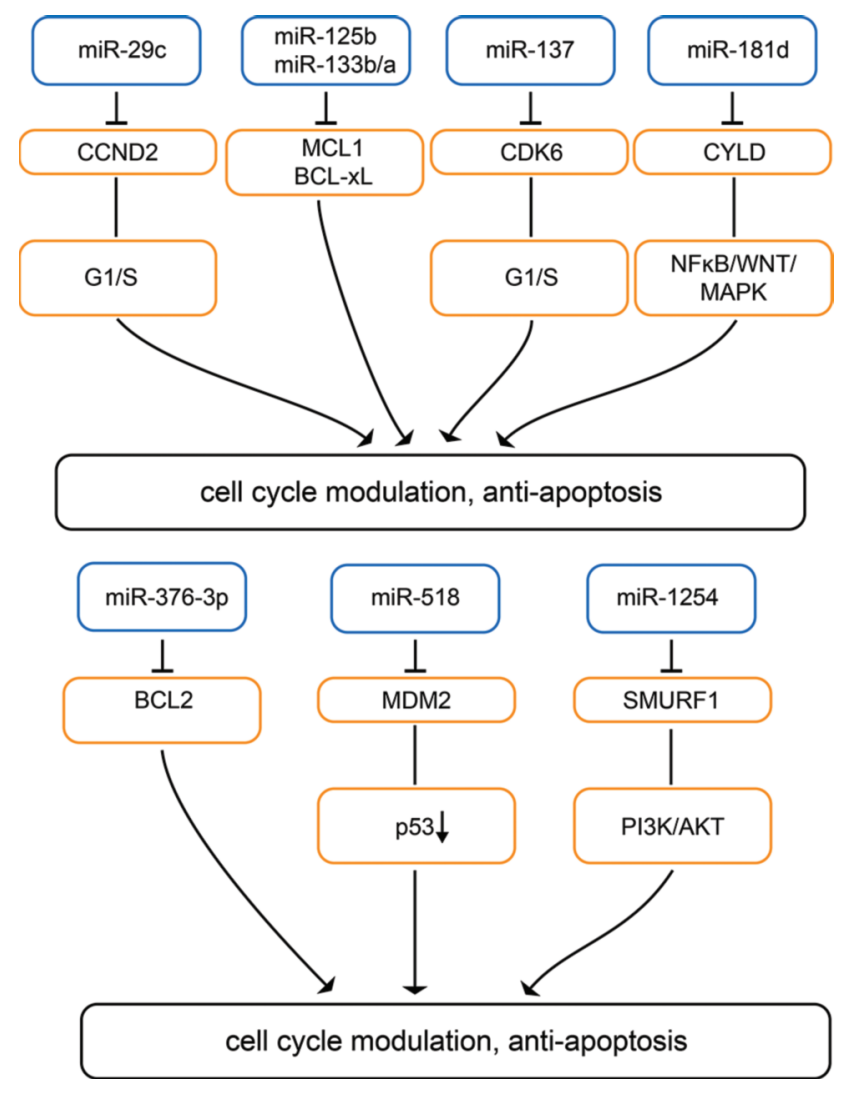

Figure 2. Tumor-suppressive miRs targeting cell-cycle related and antiapoptotic mRNAs with activity in preclinical in vivo models: miRs-29c, $-12 b,-133 b / a,-137,-181 d, 376-3 p,-518,-1254$. BCL2: B-cell lymphoma 2; BCL-xL: B-cell lymphoma extra large; CCND2: cyclin D2; CDK6: cyclin-dependent kinase 6; CYLD: cylindromatosus; G1/S: G1 and S-phase of cell cycle; MAPK: mitogen-activated protein kinase; MCL1: myeloid cell leukemia 1; MDM2: mouse double minute 2 homolog; NFxB: nuclear factor $x B$; PI3K: phosphoinosite 3-kinase; SMURF1: E3 ubiquitin-protein ligase.

being most down-regulated in GC (112). Low expression levels of miR-29c are associated with aggressive and progressive phenotypes of GC. In HGC-27 and MGC-803 GC cells, over-expression of miR-29 a, $-b$ and $-c$ suppresses cell growth, induces arrest of G1/S transition, and promotes apoptosis in vitro (112). Cyclin D2 (CCND2) and matrix metalloproteinase-2 (MMP2) were identified as direct targets of miR-29c (112). Intratumoral injection of synthetic miRs mimicking miRs-29a, -b and c inhibit TG of subcutaneously implanted HGC-27 cell xenografts in mice (112). CCND2 forms complexes with cyclin-dependent kinases 4 and $6(\mathrm{CDK} 4,6)$ and is required for $\mathrm{G} 1 / \mathrm{S}$ transition (113). MMP2 is up-regulated in different types of tumors including GC (114). Expression of CCND2 is associated with shorter survival in patients with GC (113). Based on TCGA-derived data, miR-29c is 


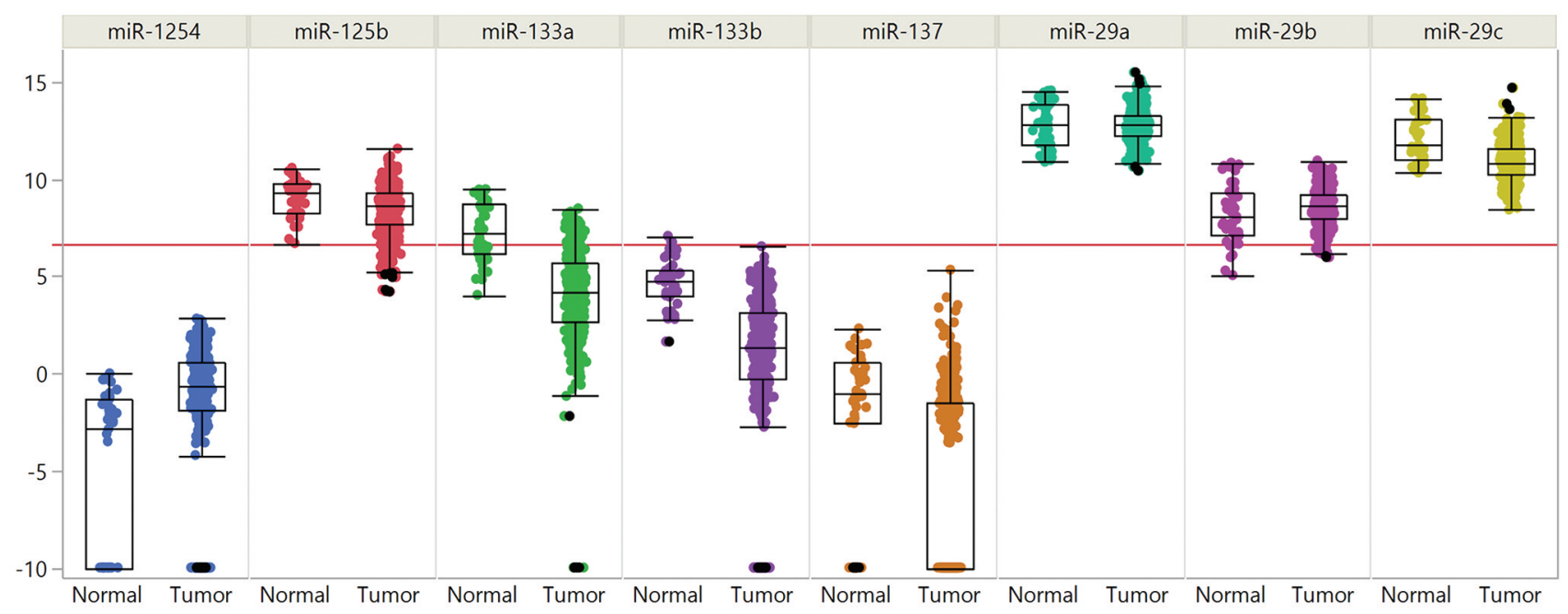

Figure 3. Expression of selected miRs in stomach adenocarcinoma compared to normal tissues. Data are shown for miR-1254, miR-125b, miR-133a, miR-133b, miR-137, miR-29a, miR-29b and miR-29c. Data from 436 tumor samples and 41 normal stomach samples derived from The Cancer Genome Atlas are shown. miR expression was quantified by RNA sequencing and is shown as log2 of normalized read counts. The red lines indicate lower versus higher expression. Expression data are shown as box plots. The line in the medium of the box represents the median value, the rectangles show the upper and lower 25\% quartiles, and 50\% of all data points are included in the greater rectangle. All of the data points, except for the outliers are located within the upper and lower whiskers.

down-regulated in GC specimens in comparison to corresponding normal tissues, in contrast to miRs- 29a and -b (Figure 3).

Mir-125b, -133b/a target MCL1 and BCL- $x$ L. miR-125b (Figure 2) is down-regulated in GC and decreased levels of miR-125b correlate with advanced clinical stage, lymph node metastases, and poor clinical outcome in GC (115). Induced myeloid leukemia cell differentiation protein (MCL-1) was identified as a target of miR-125b (115). miR-125b inhibits proliferation of MGC-803 cells and TG in nude mice after subcutaneous implantation (115). miR-133b/a (Figure 2) is down-regulated by histone modification of its promoter in GC cells (116). miR-133b/a suppresses GC cell proliferation and promotes apoptosis, delays tumor formation, and reduces tumor size of GC xenografts in nude mice (116). MCL1 and BCL-xL (B-cell lymphoma-extra large) were identified as targets of miR-133b/a (116). MCL1 is a member of the antiapoptotic BCL2 family, regulates cell growth, promotes EMT of GC cells, and its expression predicts poor outome in GC patients $(117,118)$. BCL-xL is a multifunctional antiapoptotic protein (119). BCL2 and BCL-xL mediate resistance to receptor-kinase targeted therapy in lung and gastric cancer (120). Based on TCGA data, miRs -125b, $133 \mathrm{a}$ and miR-133b are down-regulated in GC tissues in comparison to corresponding normal tissues (Figure 3).

miR-137 targets CDK6. miR-137 (Figure 2) expression correlates with better prognosis in GC patients (121). Ectopic expression of miR-137 in GC cells inhibits proliferation in vitro and in vivo by targeting cyclin-dependent kinase 6 (CDK6) (121). CDK6 inhibitor PD0332991 mediates an antiproliferative effect in GC cell lines, arrests them in the G1 phase and affects numerous oncogenic pathways such as p53, phosphinosite-3 kinase (PI3K)/AKT, RAS/ERK, c-jun$\mathrm{N}$-terminal kinase $(\mathrm{JNK}) / \mathrm{MAPK}, \mathrm{WNT} / \beta$ catenin, and SMAD signaling (122). CDK4,6 inhibitor palbociclib together with aromatase inhibitor letrozole has been approved for treatment of estrogen receptor positive breast cancer $(123,124)$. According to data derived from TCGA, miR-137 is down-regulated in GC tissues in comparison to corresponding normal tisses (Figure 3 ).

miR-181d targets CYLD. miR-181d (Figure 2) is downregulated in GC and is a predictor for bad prognosis (125). miR-181d targets the cylindromatosus gene (CYLD) and its expression inhibits proliferation and invasion of HGC-27 GC cells (125). In addition, it inhibits EMT and the PI3K/AKT pathway (125). Over-expression of miR-181 inhibits xenograft growth of HGC-27 cells after subcutaneous implantation into nude mice (125). CYLD is a lysine 63 deubiquitinylase, which modulates multiple signaling pathways such as $\mathrm{NFKB}$ and MAPK by its catalytic activity on key intermediates of these pathways (126). In GC, down-regulation of CYLD by methylation of its promoter has been noticed (127).

miR-376-3p (BCL2). miR-376-3p (Figure 2) expression is reduced in GC tissues in comparison to adjacent normal 


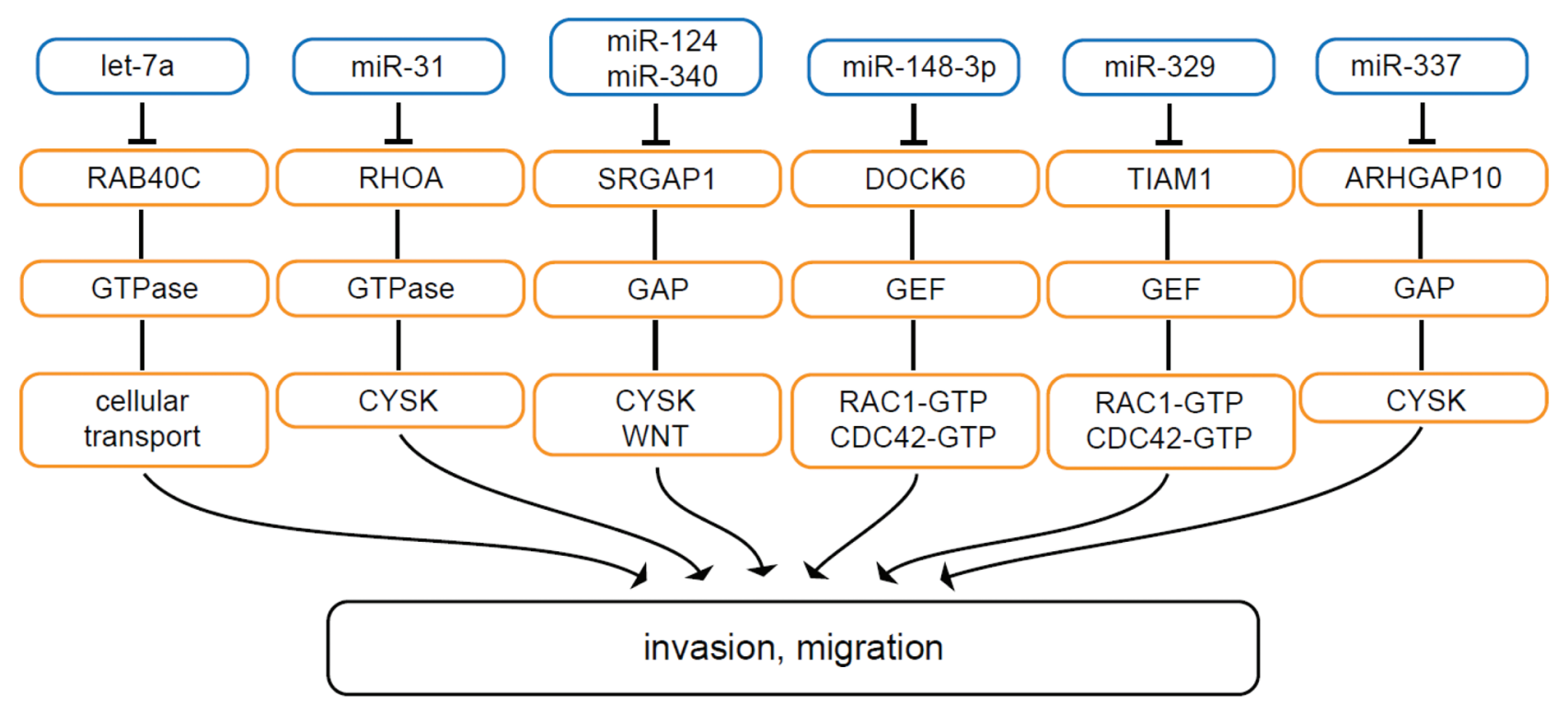

Figure 4. Tumor-suppressive miRs targeting small GTPases and and their regulatory proteins with activity in preclinical in vivo models: miRs-Let7a, 31, -124, -340, -148-3p, -329, -337. ARHGAP10: RHO GTPase activating protein 10; CDC42: cell division control protein 42; CYSK: cytoskeleton; DOCK6: dedicator of cytokinesis 6; GAP: GTPase activating protein; GEF: guanine nucleotide exchange factor; RAB40C: ras-related protein 40C; RAC1: Ras-related C3 botulinum toxin substrate 1; RHOA: Ras homolog family member A; SRGAP1: SLIT/ROBO GTPase activating protein; TIAM1: T cell lymphoma invasion and metastasis 1; WNT: WNT signaling.

tissues (128). Over-expression of miR-376-3p in SGC-7901 cells enhances apoptosis and inhibits TG of xenografts in nude mice (128). Over-expression of miR-376-3p decreases the levels of BCL2 (B-cell lymphoma 2) and increases the levels of pro-apoptotic protein BCL2 antagonist of cell death (BAD). However, it was not resolved whether BCL2 is a direct target of miR-376-3p (128). BCL2 has been shown to promote cell proliferation of GC cells (129). High Ki67/BCL2 index can predict disease free and overall survival in intestinal type GC (130).

miR-518 targets MDM2. miR-518 (Figure 2) is downregulated in GC tissues and cell lines (131). In GC cell lines MKN45 and HGC-27 miR-mimics trigger apoptosis in vitro and in vivo (131). Mouse double minute 2 homolog (MDM2) has been identified as a target of miR-518 (131). MDM2 is an E3 ubiquitin-protein ligase which ubiquitinylates p53, triggering its degradation (131). miR-518 up-regulates p53, pro-apoptotic BCL2-associated protein X (BAX), activates caspase 3 and down-regulates BCL2 in GC cells (131). MDM2 up-regulation has been frequently observed in intestinal GC and correlates with nodal and distal metastases (132). An association between MDM2 amplification and tumorigenesis has been noted (133). Targeting p53/MDM2 interaction is an important effort for cancer drug discovery approaches (134).
miR-1254 targets SMURF1. miR-1254 (Figure 2) is downregulated in human GC tissues and in GC-derived cell lines (135). Expression of miR-1254 inhibits proliferation, migration, and invasion of MGC-803 and SGC-7901 GC cell lines (135). SMAD ubiquitintion regulatory factor 1 (SMURF1) was identified as a direct target of miR-1254 (135). SMURF1 is up-regulated in human GC tissues and cell lines (135). SMURF1 expression could partially reverse the effects of miR-1254 on GC cells (135). miR-1254 inhibits EMT and negatively regulates PI3K/AKT signaling by down-regulatiing SMURF1 (135). In vivo, miR-1254 mimics decrease TG of MGC-803 and SGC-7901 xenografts in nude mice (135). SMURF1 is an E3 ubiquitin ligase which regulates cell-cycle, apoptosis, metastasis, senescence, and genomic stability. It can act, in a context-dependent manner, as a tumor promoter or suppressor (136). According to TCGA-derived expression data, miR-1254 levels are very low in GC and also in corresponding normal tisses. Therefore, the degree of deregulation in GC cannot be determined based on these data (Figure 3).

\section{Small GTPases and Proteins Modulating Their Activity}

Let-7a targets $R A B 40 C$. Expression of the microRNA (lethal7-precursor) Let-7a (Figure 4) is reduced in GC tissues and cell lines in comparison to corresponding control tissues 
and cell lines (137). Ectopic expression of let-7a mediates inhibition of proliferation, anchorage-dependent cell growth, and G1 arrest (137). BGC-823 cells transfected with let-7a mimics exhibit reduced TG after subcutaneous implantation into nude mice (137). RAB40C was identified as a direct target of miR Let-7a (137). RAB40C is a member of the RAS family of GTPases and is expressed in brain neurons and glia, is involved in vesicle transport in oligodendrocytes and plays an important role in tumorigenesis (138-140). Small GTPases, when activated transmit signaling to a variety of effector proteins after binding of GTP and hydrolyzing it to GDP (140). They are regulated by GAPs, GEFs (GTPase-activating proteins and Guanine nucleotide exchange factors) and RAS homology member family member (RHO) guanine dissocation inhibitors (GDIs). GAPs bind to activated $G$ proteins and stimulate their GTPase activity, GEFs promote the exchange of GDP by GTP and GDIs sequester RHO-GTPases in the inactive state by inhibition of dissociation of inactive guanine nucleotides (140). The role of RAB-40C in GC remains to be investigated in further detail.

miR-31 targets RHOA. Expression of miR-31 (Figure 4) is negatively correlated with GC metastasis (141). miR-31 mimics inhibit migration of BGC-823 cells and inhibition of miR-31 promotes migration of SGC-7901 cells (141). Reduced lung metastasis after tail vein injection in nude mice was found when SGC-7901 GC cells were transfected with miR-31 mimics (141). RAS homology family member A (RHOA) was identified as a direct target of miR-31 (141). RHOA is a small GTPase which can activate RHOassociated, coiled-coil containing protein kinase which phosphorylates myosin light chain (MLC) and thus exacerbates the migration and invasion capability of GC cells (142). RHOA is also associated with cytoskeleton regulation such as actin stress fiber formation and actomyosin contractibility, cell migration, and metastasis in GC (143). RHOA has potential clinical significance as a prognostic marker in GC (144). Together with cell division control protein 42 homolog (CDC42) and RAS-related botulinum toxin substrate 1 (RAC1), RHOA is one of the best studied GTPases. Tractability of RHOA as a therapeutic target is a challenging issue, as holds true for all GTPases.

miRs-124, -340 target SRGAP1. miRs-124 and -340 (Figure 4) suppress cell growth, invasion, and colony formation of GC cell lines MKN45, MGC-803, and NCI-N87 (145). SLITroundabout (ROBO) GTPase activating protein (SRGAP1) is a downstream effector SLIT/ROBO signaling and was identified as a target of miRs-124 and -340 (145). SRGAP1 over-expression is associated with poor prognosis of GC patients (145). SRGAP1 promotes xenograft formation of GC cells in nude mice (145) and induces formation of CDC42-
GTP, RHOA-GTP, and RAC1-GTP complexes (145). Furthermore, SRGAP1 promotes WNT/ $\beta$ catenin signaling thus establishing a link between SLIT/ROBO signaling and the WNT/Bcatenin pathway (145). The downstream effectors CDC42, RHOA, and RAC1 are involved in filopodia formation by stress fibers and focal adhesion complexes, as well as formation of lamellipodia $(146,147)$. SLIT/ROBO signaling was first discovered in the central nervous system, later on also in cancer as a promoter of angiogenesis, inflammatory chemotaxis, tumor cell migration, and metastasis (148). In GC, miR-340 inhibits cell proliferation and apoptosis through regulation of $\mathrm{NFkB}$ and suppressor of cytokine signaling (SOCS)/janus kinase (JAK)/STAT signaling $(149,150)$. miR-124 has been shown to suppress TG in GC xenografts in mice (151).

miR-148-3p targets DOCK6. miR-148-3p (Figure 4) targets and reduces the levels of dedicator of cytokines 6 , a guanine nucleotide exchange factor (DOCK6) (152). DOCK6 expression is increased in GC tissues and indicates poor prognosis (152). DOCK6 increases proliferation, migration, and invasion of SGC-7901 SM GC cells by activation of RAC1 and CDC42 (152). In nude mice, over-expression of miR-148-3p in SGC-7901 M cells decreased lung and liver metastasis after tail vein injection, while DOCK6 overexpression reversed inhibition of metastasis (152). DOCK6 expression is negatively correlated with with miR-148b expression in GC tissues (152). In mammals, 11 DOCK proteins have been identified as regulators of the actin cytoskeleton, cell adhesion and migration (153). The role of DOCK6 in GC needs further investigation.

miR-329 targets TIAM1. miR-329 (Figure 4) is downregulated in GC and inhibits migration and invasion of GC cells MGC-803 and HGC-27 (154). In vivo, injection of HGC-27 cells together with miR-329 mimics inhibits TG in nude mice (154). T-cell lymphoma invasion and metastasis inducing protein 1 (TIAM1) was identified as a direct target of miR-329 (154). TIAM1 acts as a GEF for activation of RAC1, but also for CDC42, and to a lesser extent for RHOA (154). Protumoral activities of TIAM1 involve modulation of the cytoskeleton, cell polarity, membrane trafficking, cell migration, adhesion, cell growth, survival, carcinogenesis, and metastasis (155). But anti-cancer activity of TIAM1 has also been reported (155). Up-regulation of TIAM1 has been reported in GC and its involvement in cell migration and invasion $(156,157)$. The propensity of GEFs and GAPs as targets for anti-cancer therapy has been discussed (158).

miR-337 targets ARHGAP10. miR-337 (Figure 4) decreases the motility and viability of SGC-7901 GC cells, although it has no impact on their proliferation (159). RHO GTPaseactivating protein 1 (ARHGAP10) was identified as a target 
of miR-337 (159). ARHGAP10 restores viability and migration capacity of SGC-7901 cells (159). In vivo, SGC7901 cells transfected with miR-337 give rise to reduced metastatic foci after tail vein injection in immunocompromized mice (159). RHO-GAPs are regulators of RHO-GTPase signaling pathways related to cytoskeletal dynamics, cell proliferation, and differentiation (160). ARHGAP10 contains a PDZ, a pleckstrin homology domain, and a RHO-GAP domain (160). However, opposite functional roles for ARHGAP10 have been reported. In lung cancer, ARHGAP10 inhibits proliferation, migration, invasion and WNT signaling (161). In colorectal cancer cells, ARHGAP10 inhibits proliferation and metastases via blocking of the RHOA/AKT signaling pathway (162). In ovarian cancer, ARHGAP10 is down-regulated and suppresses tumorigenicity (163).

\section{Therapeutic Aspects}

This review focusses on miRs that are down-regulated in GC and affect the expression of transcription factors, cell-cycle and apoptosis-related proteins, and of small GTPases and their regulatory proteins with demonstrated efficacy in preclinical in vivo models. Down-regulation of miRs can be due to aberrant miR processing, methylation of $\mathrm{CpG}$ islands in the promoter region and adjacent regions, and other epigenetic mechanisms (164-168). Replacement therapy can be achieved with miR-mimics, synthetic double-stranded RNAs that mimic the endogenous RNAs. Chemical modifications such as introduction of 2'-O-methyl, phosphorothioate and locked nucleic acids (LNA) can improve stability and targeting to the disease site (169-172). miR mimics or miRs can be injected intratumorally or systemically in designed formulations or as plasmid- or viralderived vectors (169-172). Adeno-associated vectors can transduce target cells efficiently, do not integrate, are eliminated efficiently with minimal toxicity, and have emerged as vehicles for miR-replacement therapies (173, 174). A POC experiment revealed that restoration of miR let7 was able to inhibit lung cancer in an orthotopic mouse model expressing KRAS G12D, an activating mutation of KRAS (175). Further important POC experiments reconstituting expression of miR-29b and 708-5p have been described in mouse lung cancer models $(176,177)$.

This review compiles published POC experiments for 37 selected in vivo miR replacement studies in GC-related in vivo models. The design of optimized delivery systems is of paramount importance in this context (169). Delivery systems based on modification of miRs with polyethylene glycol (PEG), neutral lipid emulsions, conjugation with N-acetyl-Dgalactosamine, chitosan-nucleic acid conjugates, glucosebased-polymers such as cyclodextrin, dendrimers, synthetic polyethylenimine based vehicles, poly (lactide or glycolide) particles or TargomiRs, bacterium-based vesicles with surface-based antibodies have been developed $(169,178)$.

Approaches towards applications of miR replacement therapy in cancer patients have focused on miR-34 (179) or miR-15/16 (180). miR-34 has been validated in numerous preclinical in vitro and in vivo studies as a candidate for replacement therapy (181). This holds true for colorectal, prostate, breast, liver, and lung cancer as well as osteosarcoma and haematological neoplasms (181). miR-34 inhibits crucial oncogenic and metastatic pathways such as EMT mediated by transcription factors SNAIL, SLUG and ZEB1,2, NOTCH-, WNT-, IL6R- and TGF $3 /$ SMAD signaling (181). MRX 34 (Mirna Therapeutics), an amphoteric, lipid nanoparticle filled with miR-34 mimics, has been evaluated in a Phase I clinical study (NCT01829971) in 155 participants in several solid tumors and haematological malignancies. That study, however, had to be terminated due to immunerelated side effects in five patients $(181,182)$. As outlined, in GC, miR-34 targets transcription factor YY1 and may be a possible agent for replacement therapy.

The other ongoing clinical study for miR-replacement therapy is based on epidermal growth factor receptor (EGFR)coated bacterial minicells (EnGene IC) expressing mimics corresponding to the miR-15/107 consensus sequence (miR-16 mimics). The delivery vehicels are nanocells also referred to as TargomiRs. The Phase I study in patients with metastatic pleural mesothelioma and advanced non-small cell lung carcinoma (NSCLC) is referred to as the mesomiR-1 study $(180,183)$. In preclincal experiments, expression of miR-16 in mesothelioma cell lines had a tumor-suppressive effect through induction of apoptosis by down-regulation of BCL2 and CCND1 (184). In a phase I study, 27 patients were enrolled with an objective response and stabilization of disease in 15 patients (183).

As of today, several issues that hamper the therapeutic application of miR-related agents remain to be resolved (185192). These issues are not discussed in detail in this review.

\section{Conclusion}

Our comprehensive review of GC-associated miRs revealed 25 down-regulated miRs that target transcription factors, 7 targeting cell-cycle/apoptosis-related genes, and 5 directed against small GTPase-related and -associated molecules such as GEFs and GAPs. These might present as candidates for potential therapeutic intervention in GC patients, in the form of replacement therapy or inhibition of the corresponding upregulated targets. The applicability of such replacement therapies is still limited by technical hurdles as described above. For target prioritization issues such as prevalence, prognostic relevance, druggability and consistent or contextdependent functional properties are important parameters for ranking. In case of transcription factors, tractability is critical because mode of intervention is difficult because it would 
involve inhibition of DNA binding or of co-factor proteinprotein interactions (193). Also, modulation of the levels of transcription factors by interfering with ubiquitinylation and subsequent proteasome degradation might be considered. Proteolysis targeting chimeras (PROTACS) directed against intrinsically disordered regions of transcription factors with Cys-reactive inhibitors and another moiety engaging an E3 ubiquitin ligase are emerging agents for interference (194). The druggability of small GTPase related molecules, GEFs and GAPs has to be categorized as critical, despite of encouraging recent developments $(195,196)$. The functions of TIAM1 (miR-329), ARHGAP10 (miR-337) and SMURF1 (miR-1254) are context-dependent as outlined. For NR2F2 (miR-27b), E2F2, RHOA (miR-31) and CYLD (miR-181d) contradictory functions have been published as described in the previous text. Prognostic data are available for miR-29 (CCND2), miR-105, -138c (SOX9, SOX4), miR-124, -130 (SRGAP1), miR-133 b/a miR-136 (HOXC10), miR-141, 200c (ZEB1, ZEB2), miR-145 (ETS1), miR-186 (HIF-1 $\alpha$ ), miR-320 (FOXM1), miR-489 (PROX1), miR-518 (MDM2) and miR-1297 (CREB1). Taken together miR-133b/a (MCL1) and miR-518 (MDM2) might present as promising targets. However, more GC specific target validation experiments are needed to derive firm conclusions. Broad drug discovery programmes for MCL1 and p53/MDM2 and clinical studies on other indications are ongoing (197-199).

\section{Conflicts of Interest}

FB, SA, and UB are and UHW was an employee of Roche.

\section{Authors' Contributions}

FB, SA, UB and UHW jointly designed and prepared the manuscript.

\section{References}

1 Van Cutsem E, Sagaert X, Topal B, Haustermans K and Prenen H: Gastric cancer. Lancet 388(10060): 2654-2664, 2016. PMID: 27156933. DOI: $10.1016 / \mathrm{S} 0140-6736(16) 30354-3$

2 Sohn BH, Hwang JE, Jang HJ, Lee HS, Oh SC, Shim JJ, Lee KW, Kim EH, Yim SY, Lee SH, Cheong JH, Jeong W, Cho JY, Kim J, Chae J, Lee J, Kang WK, Kim S, Noh SH, Ajani JA and Lee JS: Clinical significance of four molecular subtypes of gastric cancer identified by the Cancer Genome Atlas Project. Clin Cancer Res, 2017. PMID: 28747339. DOI: 10.1158/1078-0432.CCR-16-2211

3 Orditura M, Galizia G, Sforza V, Gambardella V, Fabozzi A, Laterza MM, Andreozzi F, Ventriglia J, Savastano B, Mabilia A, Lieto E, Ciardiello F and De Vita F: Treatment of gastric cancer. World J Gastroenterol 20(7): 1635-1649, 2014. PMID: 24587643. DOI: $10.3748 /$ wjg.v20.i7.1635

4 Bonelli P, Borrelli A, Tuccillo FM, Silvestro L, Palaia R and Buonaguro FM: Precision medicine in gastric cancer. World $\mathrm{J}$ Gastrointest Oncol 11(10): 804-829, 2019. PMID: 31662821. DOI: $10.4251 /$ wjgo.v11.i10.804
5 Riihimäki M, Hemminki A, Sundquist K, Sundquist J and Hemminki K: Metastatic spread in patients with gastric cancer. Oncotarget 7(32): 52307-52316, 2016. PMID: 27447571. DOI: 10.18632 /oncotarget. 10740

6 Tahara E: Genetic alterations in human gastrointestinal cancers. The application to molecular diagnosis. Cancer 75(6 Suppl): 14101417, 1995. PMID: 7889467. DOI: 10.1002/10970142(19950315)75:6+<1410::aid-cncr2820751504>3.0.co;2-o

7 Saha A, Wittmeyer J and Cairns BR: Chromatin remodelling: the industrial revolution of DNA around histones. Nat Rev Mol Cell Biol 7(6): 437-447, 2006. PMID: 16723979. DOI: 10.1038/ nrm1945

8 Yaniv M: Chromatin remodeling: from transcription to cancer. Cancer Genet 207(9): 352-357, 2014. PMID: 24825771. DOI: 10.1016/j.cancergen.2014.03.006

9 Lin Y, Wu Z, Guo W and Li J: Gene mutations in gastric cancer: a review of recent next-generation sequencing studies. Tumour Biol 36(10): 7385-7394, 2015. PMID: 26364057. DOI: 10.1007/s13277-015-4002-1

10 Karlsson R, Pedersen ED, Wang Z and Brakebusch C: Rho GTPase function in tumorigenesis. Biochim Biophys Acta 1796(2): 91-98, 2009. PMID: 19327386. DOI: 10.1016/j.bbcan. 2009.03.003

11 Wheeler AP and Ridley AJ: Why three Rho proteins? RhoA, RhoB, RhoC, and cell motility. Exp Cell Res 301(1): 43-49, 2004. PMID: 15501444. DOI: 10.1016/j.yexcr.2004.08.012

12 Bartel DP: Metazoan MicroRNAs. Cell 173(1): 20-51, 2018. PMID: 29570994. DOI: 10.1016/j.cell.2018.03.006

$13 \mathrm{Li} \mathrm{Z}$ and Rana TM: Therapeutic targeting of microRNAs: current status and future challenges. Nat Rev Drug Discov 13(8): 622638, 2014. PMID: 25011539. DOI: 10.1038/nrd4359

14 Lam JK, Chow MY, Zhang Y and Leung SW: siRNA versus miRNA as therapeutics for gene silencing. Mol Ther Nucleic Acids 4: e252, 2015. PMID: 26372022. DOI: 10.1038/mtna.2015.23

15 Peter ME: Targeting of mRNAs by multiple miRNAs: the next step. Oncogene 29(15): 2161-2164, 2010. PMID: 20190803. DOI: 10.1038/onc. 2010.59

16 Lin S and Gregory RI: MicroRNA biogenesis pathways in cancer. Nat Rev Cancer 15(6): 321-333, 2015. PMID: 25998712. DOI: 10.1038/nrc3932

17 Pekarsky Y, Balatti V and Croce CM: BCL2 and miR-15/16: from gene discovery to treatment. Cell Death Differ 25(1): 21-26, 2018. PMID: 28984869. DOI: 10.1038/cdd.2017.159

18 Callegari E, Elamin BK, Giannone F, Milazzo M, Altavilla G, Fornari F, Giacomelli L, D'Abundo L, Ferracin M, Bassi C, Zagatti B, Corrà F, Miotto E, Lupini L, Bolondi L, Gramantieri L, Croce CM, Sabbioni S and Negrini M: Liver tumorigenicity promoted by microRNA-221 in a mouse transgenic model. Hepatology 56(3): 1025-1033, 2012. PMID: 22473819. DOI: 10.1002/hep. 25747

19 Hata A and Kashima R: Dysregulation of microRNA biogenesis machinery in cancer. Crit Rev Biochem Mol Biol 51(3): 121-134, 2016. PMID: 26628006. DOI: 10.3109/10409238.2015.1117054

20 Weidle UH, Dickopf S, Hintermair C, Kollmorgen G, Birzele F and Brinkmann U: The role of micro RNAs in breast cancer metastasis: Preclinical validation and potential therapeutic targets. Cancer Genomics Proteomics 15(1): 17-39, 2018. PMID: 29275360. DOI: $10.21873 /$ cgp.20062

21 Weidle UH, Birzele F, Kollmorgen G and Nopora A: Potential microRNA-related targets for therapeutic intervention with 
ovarian cancer metastasis. Cancer Genomics Proteomics 15(1): 1-15, 2018. PMID: 29275359. DOI: 10.21873/cgp.20061

22 Weidle UH, Epp A, Birzele F and Brinkmann U: The functional role of prostate cancer metastasis-related micro-RNAs. Cancer Genomics Proteomics 16(1): 1-19, 2019. PMID: 30587496. DOI: $10.21873 / \operatorname{cgp} .20108$

23 Weidle UH, Birzele F and Nopora A: MicroRNAs as potential targets for therapeutic intervention with metastasis of non-small cell lung cancer. Cancer Genomics Proteomics 16(2): 99-119, 2019. PMID: 30850362. DOI: $10.21873 /$ cgp.20116

24 Weidle UH, Birzele F and Nopora A: Pancreatic ductal adenocarcinoma: MicroRNAs affecting tumor growth and metastasis in preclinical in vivo models. Cancer Genomics Proteomics 16(6): 451-464, 2019. PMID: 31659100. DOI: $10.21873 / \operatorname{cgp} .20149$

25 Weidle UH, Schmid D, Birzele F and Brinkmann U: MicroRNAs involved in metastasis of hepatocellular carcinoma: Target candidates, functionality and efficacy in animal models and prognostic relevance. Cancer Genomics Proteomics 17(1): 1-21, 2020. PMID: 31882547 . DOI: $10.21873 /$ cgp.20163

26 Wang T, Hou J, Li Z, Zheng Z, Wei J, Song D, Hu T, Wu Q, Yang JY and Cai JC: miR-15a-3p and miR-16-1-3p negatively regulate Twist1 to repress gastric cancer cell invasion and metastasis. Int J Biol Sci 13(1): 122-134, 2017. PMID: 28123352. DOI: 10.7150/ijbs.14770

27 Martin A and Cano A: Tumorigenesis: Twist1 links EMT to selfrenewal. Nat Cell Biol 12(10): 924-925, 2010. PMID: 20885418. DOI: 10.1038/ncb1010-924

28 Yan-Qi Z, Xue-Yan G, Shuang H, Yu C, Fu-Lin G, Fei-Hu B, ShiRen S, Xu-Feng W, Jie D and Dai-Ming F: Expression and significance of TWIST basic helix-loop-helix protein overexpression in gastric cancer. Pathology 39(5): 470-475, 2007. PMID: 17886095. DOI: 10.1080/00313020701570053

29 Takei Y, Shen G, Morita-Kondo A, Hara T, Mihara K and Yanagihara K: MicroRNAs associated with epithelialmesenchymal transition can be targeted to inhibit peritoneal dissemination of human scirrhous gastric cancers. Pathobiology 85(4): 232-246, 2018. PMID: 29847827. DOI: 10.1159/ 000488801

30 Su J, Zhang A, Shi Z, Ma F, Pu P, Wang T, Zhang J, Kang C and Zhang Q: MicroRNA-200a suppresses the Wnt/ $\beta$-catenin signaling pathway by interacting with $\beta$-catenin. Int J Oncol 40(4): 1162-1170, 2012. PMID: 22211245. DOI: 10.3892/ ijo.2011.1322

31 Cong N, Du P, Zhang A, Shen F, Su J, Pu P, Wang T, Zjang J, Kang $\mathrm{C}$ and Zhang Q: Downregulated microRNA-200a promotes EMT and tumor growth through the wnt/ $\beta$-catenin pathway by targeting the E-cadherin repressors ZEB1/ZEB2 in gastric adenocarcinoma. Oncol Rep 29(4): 1579-1587, 2013. PMID: 23381389. DOI: 10.3892/or.2013.2267

32 Song F, Yang D, Liu B, Guo Y, Zheng H, Li L, Wang T, Yu J, Zhao Y, Niu R, Liang H, Winkler H, Zhang W, Hao X and Chen K: Integrated microRNA network analyses identify a poor-prognosis subtype of gastric cancer characterized by the miR-200 family. Clin Cancer Res 20(4): 878-889, 2014. PMID: 24352645. DOI: 10.1158/1078-0432.CCR-13-1844

33 Nieszporek A, Skrzypek K, Adamek G and Majka M: Molecular mechanisms of epithelial to mesenchymal transition in tumor metastasis. Acta Biochim Pol 66(4): 509-520, 2019. PMID: 31883362. DOI: 10.18388/abp.2019_2899
34 Tania M, Khan MA and Fu J: Epithelial to mesenchymal transition inducing transcription factors and metastatic cancer. Tumour Biol 35(8): 7335-7342, 2014. PMID: 24880591. DOI: 10.1007/s13277014-2163-y

35 Chen H, Lu W, Huang C, Ding K, Xia D, Wu Y and Cai M: Prognostic significance of ZEB1 and ZEB2 in digestive cancers: a cohort-based analysis and secondary analysis. Oncotarget $8(19)$ : 31435-31448, 2017. PMID: 28416756. DOI: 10.18632/ oncotarget.15634

36 Jin M, Zhang GW, Shan CL, Zhang H, Wang ZG, Liu SQ and Wang SQ: Up-regulation of miRNA-105 inhibits the progression of gastric carcinoma by directly targeting SOX9. Eur Rev Med Pharmacol Sci 23(9): 3779-3789, 2019. PMID: 31115004. DOI: 10.26355/eurrev_201905_17804

37 Shang JC, Yu GZ, Ji ZW, Wang XQ and Xia L: MiR-105 inhibits gastric cancer cells metastasis, epithelial-mesenchymal transition by targeting SOX9. Eur Rev Med Pharmacol Sci 23(14): 61606169, 2019. PMID: 31364116. DOI: 10.26355/eurrev_ 201907_18429

38 Pang L, Li B, Zheng B, Niu L and Ge L: miR-138 inhibits gastric cancer growth by suppressing SOX4. Oncol Rep 38(2): 12951302, 2017. PMID: 28656304. DOI: 10.3892/or.2017.5745

39 Kumar P and Mistri TK: Transcription factors in SOX family: Potent regulators for cancer initiation and development in the human body. Semin Cancer Biol 67(Pt 1): 105-113, 2020. PMID: 31288067. DOI: 10.1016/j.semcancer.2019.06.016

40 Grimm D, Bauer J, Wise P, Krüger M, Simonsen U, Wehland M, Infanger $\mathrm{M}$ and Corydon TJ: The role of SOX family members in solid tumours and metastasis. Semin Cancer Biol 67(Pt 1): 122153, 2020. PMID: 30914279. DOI: 10.1016/j.semcancer. 2019.03.004

41 Chen J, Ju HL, Yuan XY, Wang TJ and Lai BQ: SOX4 is a potential prognostic factor in human cancers: a systematic review and meta-analysis. Clin Transl Oncol 18(1): 65-72, 2016. PMID: 26250764. DOI: 10.1007/s12094-015-1337-4

42 Carrasco-Garcia E, Álvarez-Satta M, García-Puga M, Ribeiro ML, Arevalo S, Arauzo-Bravo M and Matheu A: Therapeutic relevance of SOX9 stem cell factor in gastric cancer. Expert Opin Ther Targets 23(2): 143-152, 2019. PMID: 30572738. DOI: $10.1080 / 14728222.2019 .1559826$

43 Zheng J, Ge P, Liu X, Wei J, Wu G and Li X: MiR-136 inhibits gastric cancer-specific peritoneal metastasis by targeting HOXC10. Tumour Biol 39(6): 1010428317706207, 2017. PMID: 28656883. DOI: $10.1177 / 1010428317706207$

44 Luo Z, Rhie SK and Farnham PJ: The enigmatic HOX genes: Can we crack their code? Cancers (Basel) 11(3): 323, 2019. PMID: 30866492. DOI: 10.3390/cancers11030323

45 Kim J, Bae DH, Kim JH, Song KS, Kim YS and Kim SY: HOXC10 overexpression promotes cell proliferation and migration in gastric cancer. Oncol Rep 42(1): 202-212, 2019. PMID: 31115563. DOI: 10.3892/or.2019.7164

46 Guo C, Hou J, Ao S, Deng X and Lyu G: HOXC10 up-regulation promotes gastric cancer cell proliferation and metastasis through MAPK pathway. Chin J Cancer Res 29(6): 572-580, 2017. PMID: 29353980. DOI: 10.21147/j.issn.1000-9604.2017.06.12

47 Yao S, He L, Zhang Y, Ye L, Lai Y, Huang L, Wu L, Wu G and Zhu S: HOXC10 promotes gastric cancer cell invasion and migration via regulation of the NF-kB pathway. Biochem Biophys Res Commun 501(3): 628-635, 2018. PMID: 29753747. DOI: 10.1016/j.bbrc.2018.05.019 
48 Li J, Tong G, Huang C, Luo Y, Wang S, Zhang Y, Cheng B, Zhang Z, Wu X, Liu Q, Li M, Li L and Ni B: HOXC10 promotes cell migration, invasion, and tumor growth in gastric carcinoma cells through upregulating proinflammatory cytokines. J Cell Physiol 235(4): 3579-3591, 2020. PMID: 31552684. DOI: 10.1002/jcp.29246

49 Zhang B, Ji S, Ma F, Ma Q, Lu X and Chen X: miR-489 acts as a tumor suppressor in human gastric cancer by targeting PROX1. Am J Cancer Res 6(9): 2021-2030, 2016. PMID: 27725907.

50 Ueta K, Otowa Y, Kakeji Y and Hirashima M: PROX1 is associated with cancer progression and prognosis in gastric cancer. Anticancer Res 38(11): 6139-6145, 2018. PMID: 30396930. DOI: 10.21873/anticanres.12966

51 Park KJ, Cho SB, Park YL, Kim N, Park SY, Myung DS, Lee WS, Kweon SS and Joo YE: Prospero homeobox 1 mediates the progression of gastric cancer by inducing tumor cell proliferation and lymphangiogenesis. Gastric Cancer 20(1): 104-115, 2017. PMID: 26759228. DOI: 10.1007/s10120-015-0592-y

52 Feng Q, Wu X, Li F, Ning B, Lu X, Zhang Y, Pan Y and Guan W: miR-27b inhibits gastric cancer metastasis by targeting NR2F2. Protein Cell 8(2): 114-122, 2017. PMID: 27844448. DOI: 10.1007/s 13238-016-0340-z

53 Safe S, Jin UH, Hedrick E, Reeder A and Lee SO: Minireview: role of orphan nuclear receptors in cancer and potential as drug targets. Mol Endocrinol 28(2): 157-172, 2014. PMID: 24295738. DOI: $10.1210 /$ me.2013-1291

54 Polvani S, Pepe S, Milani S and Galli A: COUP-TFII in health and disease. Cells 9(1): 101, 2019. PMID: 31906104. DOI: 10.3390/cells9010101

55 Bringuier PP, Schalken JA, Hervieu V and Giroldi LA: Involvement of orphan nuclear receptor COUP-TFII in cadherin6 and cadherin-11 regulation: implications in development and cancer. Mech Dev 136: 64-72, 2015. PMID: 25687954. DOI: 10.1016/j.mod.2015.02.001

56 Ding W, Zhang Y, Cai H, Liu G, Ye Y, Xu G, Wang H, Xiong D, Zhang C, Huang Z and Luo Q: Overexpression of COUP TFII suppresses proliferation and metastasis of human gastric cancer cells. Mol Med Rep 17(2): 2393-2401, 2018. PMID: 29207189. DOI: $10.3892 / \mathrm{mmr} .2017 .8164$

57 Wang H, Zhang X, Liu Y, Ni Z, Lin Y, Duan Z, Shi Y, Wang G and Li F: Downregulated miR-31 level associates with poor prognosis of gastric cancer and its restoration suppresses tumor cell malignant phenotypes by inhibiting E2F2. Oncotarget 7(24): 36577-36589, 2016. PMID: 27174918. DOI: 10.18632/ oncotarget.9288

58 Kent LN and Leone G: The broken cycle: E2F dysfunction in cancer. Nat Rev Cancer 19(6): 326-338, 2019. PMID: 31053804. DOI: $10.1038 / \mathrm{s} 41568-019-0143-7$

59 Manicum T, Ni F, Ye Y, Fan X and Chen BC: Prognostic values of E2F mRNA expression in human gastric cancer. Biosci Rep 38(6): BSR20181264, 2018. PMID: 30487158. DOI: 10.1042/ BSR20181264

60 Yin H, Song P, Su R, Yang G, Dong L, Luo M, Wang B, Gong B, Liu C, Song W, Wang F, Ma Y, Zhang J, Wang W and Yu J: DNA Methylation mediated down-regulating of MicroRNA-33b and its role in gastric cancer. Sci Rep 6: 18824, 2016. PMID: 26729612. DOI: $10.1038 /$ srep18824

61 He W, Li Y, Chen X, Lu L, Tang B, Wang Z, Pan Y, Cai S, He Y and Ke Z: miR-494 acts as an anti-oncogene in gastric carcinoma by targeting c-myc. J Gastroenterol Hepatol 29(7): 1427-1434, 2014. PMID: 24612089. DOI: 10.1111/jgh.12558
62 Lüscher B: Function and regulation of the transcription factors of the Myc/Max/Mad network. Gene 277(1-2): 1-14, 2001. PMID: 11602341. DOI: 10.1016/s0378-1119(01)00697-7

63 Schuhmacher M, Staege MS, Pajic A, Polack A, Weidle UH, Bornkamm GW, Eick D and Kohlhuber F: Control of cell growth by c-Myc in the absence of cell division. Curr Biol 9(21): 12551258, 1999. PMID: 10556095. DOI: 10.1016/s0960-9822(99) 80507-7

64 Schuhmacher M, Kohlhuber F, Hölzel M, Kaiser C, Burtscher H, Jarsch M, Bornkamm GW, Laux G, Polack A, Weidle UH and Eick D: The transcriptional program of a human B cell line in response to Myc. Nucleic Acids Res 29(2): 397-406, 2001. PMID: 11139609. DOI: 10.1093/nar/29.2.397

65 Schlosser I, Hölzel M, Mürnseer M, Burtscher H, Weidle UH and Eick D: A role for c-Myc in the regulation of ribosomal RNA processing. Nucleic Acids Res 31(21): 6148-6156, 2003. PMID: 14576301. DOI: $10.1093 / \mathrm{nar} / \mathrm{gkg} 794$

66 Schlosser I, Hölzel M, Hoffmann R, Burtscher H, Kohlhuber F, Schuhmacher M, Chapman R, Weidle UH and Eick D: Dissection of transcriptional programmes in response to serum and c-Myc in a human B-cell line. Oncogene 24(3): 520-524, 2005. PMID: 15516975. DOI: 10.1038/sj.onc. 1208198

67 Calcagno DQ, Leal MF, Assumpcao PP, Smith MA and Burbano RR: MYC and gastric adenocarcinoma carcinogenesis. World J Gastroenterol 14(39): 5962-5968, 2008. PMID: 18932273. DOI: $10.3748 /$ wjg. 14.5962

68 Wang AM, Huang TT, Hsu KW, Huang KH, Fang WL, Yang MH, Lo SS, Chi CW, Lin JJ and Yeh TS: Yin Yang 1 is a target of microRNA-34 family and contributes to gastric carcinogenesis. Oncotarget 5(13): 5002-5016, 2014. PMID: 24970812. DOI: 10.18632/oncotarget.2073

69 Sarvagalla S, Kolapalli SP and Vallabhapurapu S: The two sides of YY1 in cancer: A friend and a foe. Front Oncol 9: 1230, 2019. PMID: 31824839. DOI: 10.3389/fonc.2019.01230

70 Khachigian LM: The Yin and Yang of YY1 in tumor growth and suppression. Int J Cancer 143(3): 460-465, 2018. PMID: 29322514. DOI: $10.1002 /$ ijc. 31255

71 Kang W, Tong JH, Chan AW, Zhao J, Dong Y, Wang S, Yang W, Sin FM, Ng SS, Yu J, Cheng AS and To KF: Yin Yang 1 contributes to gastric carcinogenesis and its nuclear expression correlates with shorter survival in patients with early stage gastric adenocarcinoma. J Transl Med 12: 80, 2014. PMID: 24674326. DOI: $10.1186 / 1479-5876-12-80$

72 Hays E and Bonavida B: YY1 regulates cancer cell immune resistance by modulating PD-L1 expression. Drug Resist Updat 43: 10-28, 2019. PMID: 31005030. DOI: 10.1016/j.drup.2019.04.001

73 Zheng L, Pu J, Qi T, Qi M, Li D, Xiang X, Huang K and Tong Q: miRNA-145 targets v-ets erythroblastosis virus E26 oncogene homolog 1 to suppress the invasion, metastasis, and angiogenesis of gastric cancer cells. Mol Cancer Res 11(2): 182-193, 2013. PMID: 23233482. DOI: 10.1158/1541-7786.MCR-12-0534

74 Seth A and Papas TS: The c-ets-1 proto-oncogene has oncogenic activity and is positively autoregulated. Oncogene 5(12): 17611767, 1990. PMID: 2284095.

75 Seth A and Watson DK: ETS transcription factors and their emerging roles in human cancer. Eur J Cancer 41(16): 2462-2478, 2005. PMID: 16213704. DOI: 10.1016/j.ejca.2005.08.013

76 Dittmer J: The role of the transcription factor Ets1 in carcinoma. Semin Cancer Biol 35: 20-38, 2015. PMID: 26392377. DOI: 10.1016/j.semcancer.2015.09.010 
77 Tsutsumi S, Kuwano H, Nagashima N, Shimura T, Mochiki E and Asao T: Ets-1 expression in gastric cancer. Hepatogastroenterology 52(62): 654-656, 2005. PMID: 15816498.

78 Liu L, Wang Y, Bai R, Yang K and Tian Z: MiR-186 inhibited aerobic glycolysis in gastric cancer via HIF-1 $\alpha$ regulation. Oncogenesis 6(4): e318, 2017. PMID: 28414319. DOI: 10.1038/ oncsis.2017.20

79 Yang SW, Zhang ZG, Hao YX, Zhao YL, Qian F, Shi Y, Li PA, Liu CY and Yu PW: HIF-1 $\alpha$ induces the epithelial-mesenchymal transition in gastric cancer stem cells through the Snail pathway. Oncotarget 8(6): 9535-9545, 2017. PMID: 28076840. DOI: 10.18632/oncotarget.14484

$80 \mathrm{Li} \mathrm{H}$, Jia Y and Wang Y: Targeting HIF-1 $\alpha$ signaling pathway for gastric cancer treatment. Pharmazie 74(1): 3-7, 2019. PMID: 30782242. DOI: $10.1691 / \mathrm{ph} .2019 .8674$

81 Zhu CL, Huang Q, Liu CH, Lin XS and Xie F: Prognostic value of HIF- $1 \alpha$ expression in patients with gastric cancer. Mol Biol Rep 40(11): 6055-6062, 2013. PMID: 24057269. DOI: 10.1007/ s11033-013-2715-z

82 Lin S, Ma R, Zheng XY, Yu H, Liang X, Lin H and Cai XJ: Metaanalysis of immunohistochemical expression of hypoxia inducible factor- $1 \alpha$ as a prognostic role in gastric cancer. World $\mathrm{J}$ Gastroenterol 20(4): 1107-1113, 2014. PMID: 24574785. DOI: 10.3748/wjg.v20.i4.1107

83 Wang Y, Zeng J, Pan J, Geng X, Li L, Wu J, Song P, Wang Y, Liu $\mathrm{J}$ and Wang L: MiR-320a inhibits gastric carcinoma by targeting activity in the FoxM1-P27KIP1 axis. Oncotarget 7(20): 2927529286, 2016. PMID: 27086911. DOI: 10.18632/oncotarget.8676

84 Myatt SS and Lam EW: The emerging roles of forkhead box (Fox) proteins in cancer. Nat Rev Cancer 7(11): 847-859, 2007. PMID: 17943136. DOI: $10.1038 / \mathrm{nrc} 2223$

85 Borhani S and Gartel AL: FOXM1: a potential therapeutic target in human solid cancers. Expert Opin Ther Targets 24(3): 205-217, 2020. PMID: 32067537. DOI: 10.1080/14728222.2020.1727888

86 Yang L, Cui M, Zhang L and Song L: FOXM1 facilitates gastric cancer cell migration and invasion by inducing Cathepsin D. Oncotarget 8(40): 68180-68190, 2017. PMID: 28978107. DOI: 10.18632/oncotarget.19254

87 Ai C, Zhang J, Lian S, Ma J, Győrffy B, Qian Z, Han Y and Feng Q: FOXM1 functions collaboratively with PLAU to promote gastric cancer progression. J Cancer 11(4): 788-794, 2020. PMID: 31949481. DOI: $10.7150 /$ jca.37323

88 Li L, Wu D, Yu Q, Li L and Wu P: Prognostic value of FOXM1 in solid tumors: a systematic review and meta-analysis. Oncotarget 8(19): 32298-32308, 2017. PMID: 28427178. DOI: 10.18632/oncotarget.15764

89 Huang T, Kang W, Zhang B, Wu F, Dong Y, Tong JH, Yang W, Zhou Y, Zhang L, Cheng AS, Yu J and To KF: miR-508-3p concordantly silences NFKB1 and RELA to inactivate canonical NF-kB signaling in gastric carcinogenesis. Mol Cancer 15: 9, 2016. PMID: 26801246. DOI: 10.1186/s12943-016-0493-7

90 Sokolova $\mathrm{O}$ and Naumann M: NF-kB signaling in gastric cancer. Toxins (Basel) 9(4): 119, 2017. PMID: 28350359. DOI: 10.3390/toxins9040119

91 Grivennikov SI and Karin M: Dangerous liaisons: STAT3 and NFkappaB collaboration and crosstalk in cancer. Cytokine Growth Factor Rev 21(1): 11-19, 2010. PMID: 20018552. DOI: 10.1016/ j.cytogfr.2009.11.005

92 Liu H, Du F, Sun L, Wu Q, Wu J, Tong M, Wang X, Wang Q, Cao T, Gao X, Cao J, Wu N, Nie Y, Fan D, Lu Y and Zhao X: GATA6 suppresses migration and metastasis by regulating the miR520b/CREB1 axis in gastric cancer. Cell Death Dis 10(2): 35, 2019. PMID: 30674866. DOI: 10.1038/s41419-018-1270-x

93 Maeda M, Ohashi K and Ohashi-Kobayashi A: Further extension of mammalian GATA-6. Dev Growth Differ 47(9): 591-600, 2005. PMID: 16316404. DOI: 10.1111/j.1440-169X.2005.00837.x

94 Gao W, Cao Y, Guo P, Bao X, Zhu H, Zheng J, Yao C, Chen D, Yu S, Chen B, Zhou S, Pang D and Chen W: Downregulation of MiR-1297 predicts poor prognosis and enhances gastric cancer cell growth by targeting CREB1. Biomed Pharmacother 105: 413419, 2018. PMID: 29870889. DOI: 10.1016/j.biopha.2018.05.094

95 Rao M, Zhu Y, Cong X and Li Q: Knockdown of CREB1 inhibits tumor growth of human gastric cancer in vitro and in vivo. Oncol Rep 37(6): 3361-3368, 2017. PMID: 28498439. DOI: 10.3892/ or.2017.5636

96 Wang YW, Chen X, Gao JW, Zhang H, Ma RR, Gao ZH and Gao $\mathrm{P}$ : High expression of cAMP-responsive element-binding protein 1 (CREB1) is associated with metastasis, tumor stage and poor outcome in gastric cancer. Oncotarget 6(12): 10646-10657, 2015. PMID: 25825983. DOI: 10.18632/oncotarget.3392

97 Kang W, Tong JH, Lung RW, Dong Y, Zhao J, Liang Q, Zhang L, Pan Y, Yang W, Pang JC, Cheng AS, Yu J and To KF: Targeting of YAP1 by microRNA-15a and microRNA-16-1 exerts tumor suppressor function in gastric adenocarcinoma. Mol Cancer 14: 52, 2015. PMID: 25743273. DOI: 10.1186/s12943-015-0323-3

98 Zuo QF, Zhang R, Li BS, Zhao YL, Zhuang Y, Yu T, Gong L, Li S, Xiao B and Zou QM: MicroRNA-141 inhibits tumor growth and metastasis in gastric cancer by directly targeting transcriptional co-activator with PDZ-binding motif, TAZ. Cell Death Dis 6: e1623, 2015. PMID: 25633292. DOI: 10.1038/ cddis.2014.573

99 Kang W, Cheng AS, Yu J and To KF: Emerging role of Hippo pathway in gastric and other gastrointestinal cancers. World J Gastroenterol 22(3): 1279-1288, 2016. PMID: 26811664. DOI: 10.3748/wjg.v22.i3.1279

100 Zhou Y, Huang T, Cheng AS, Yu J, Kang W and To KF: The TEAD family and its oncogenic role in promoting tumorigenesis. Int J Mol Sci 17(1): 138, 2016. PMID: 26805820. DOI: 10.3390/ijms 17010138

101 Thompson BJ: YAP/TAZ: Drivers of tumor growth, metastasis, and resistance to therapy. Bioessays 42(5): e1900162, 2020. PMID: 32128850. DOI: 10.1002/bies.201900162

102 Choi W, Kim J, Park J, Lee DH, Hwang D, Kim JH, Ashktorab H, Smoot D, Kim SY, Choi C, Koh GY and Lim DS: YAP/TAZ initiates gastric tumorigenesis via upregulation of MYC. Cancer Res 78(12): 3306-3320, 2018. PMID: 29669762. DOI: 10.1158/ 0008-5472.CAN-17-3487

103 Ge L, Li DS, Chen F, Feng JD, Li B and Wang TJ: TAZ overexpression is associated with epithelial-mesenchymal transition in cisplatin-resistant gastric cancer cells. Int J Oncol 51(1): 307315, 2017. PMID: 28534974. DOI: 10.3892/ijo.2017.3998

104 Melucci E, Casini B, Ronchetti L, Pizzuti L, Sperati F, Pallocca M, De Nicola F, Goeman F, Gallo E, Amoreo CA, Sergi D, Terrenato I, Vici P, Di Lauro L, Diodoro MG, Pescarmona E, Barba M, Mazzotta M, Mottolese M, Fanciulli M, Ciliberto G, De Maria R, Buglioni S and Maugeri-Saccà M: Expression of the Hippo transducer TAZ in association with WNT pathway mutations impacts survival outcomes in advanced gastric cancer patients treated with first-line chemotherapy. J Transl Med 16(1): 22, 2018. PMID: 29402328. DOI: 10.1186/s12967-018-1385-y 
105 Kang W, Tong JH, Chan AW, Lee TL, Lung RW, Leung PP, So KK, Wu K, Fan D, Yu J, Sung JJ and To KF: Yes-associated protein 1 exhibits oncogenic property in gastric cancer and its nuclear accumulation associates with poor prognosis. Clin Cancer Res 17(8): 2130-2139, 2011. PMID: 21346147. DOI: 10.1158/ 1078-0432.CCR-10-2467

106 Wang H, Xiong M, Hu Y, Sun Y and Ma Q: MicroRNA-19b inhibits proliferation of gastric cancer cells by targeting B-cell CLL/lymphoma 3. Oncol Rep 36(4): 2079-2086, 2016. PMID: 27572553. DOI: $10.3892 /$ or.2016.5029

107 Maldonado V and Melendez-Zajgla J: Role of Bcl-3 in solid tumors. Mol Cancer 10: 152, 2011. PMID: 22195643. DOI: 10.1186/1476-4598-10-152

108 Bours V, Franzoso G, Azarenko V, Park S, Kanno T, Brown K and Siebenlist U: The oncoprotein Bcl-3 directly transactivates through kappa B motifs via association with DNA-binding p50B homodimers. Cell 72(5): 729-739, 1993. PMID: 8453667. DOI: 10.1016/0092-8674(93)90401-b

109 Li C, Nie H, Wang M, Su L, Li J, Yu B, Wei M, Ju J, Yu Y, Yan M, Gu Q, Zhu Z and Liu B: MicroRNA-409-3p regulates cell proliferation and apoptosis by targeting PHF10 in gastric cancer. Cancer Lett 320(2): 189-197, 2012. PMID: 22388101. DOI: 10.1016/j.canlet.2012.02.030

110 Banga SS, Peng L, Dasgupta T, Palejwala V and Ozer HL: PHF10 is required for cell proliferation in normal and SV40-immortalized human fibroblast cells. Cytogenet Genome Res 126(3): 227-242, 2009. PMID: 20068294. DOI: 10.1159/000251960

111 Wei M, Liu B, Su L, Li J, Zhang J, Yu Y, Yan M, Yang Z, Chen X, Liu J, Lv X, Nie H, Zhang Q, Zheng Z, Yu B, Ji J, Zhang J, Zhu $\mathrm{Z}$ and $\mathrm{Gu} \mathrm{Q}$ : A novel plant homeodomain finger 10-mediated antiapoptotic mechanism involving repression of caspase- 3 in gastric cancer cells. Mol Cancer Ther 9(6): 1764-1774, 2010. PMID: 20530714. DOI: 10.1158/1535-7163.MCT-09-1162

112 Gong J, Li J, Wang Y, Liu C, Jia H, Jiang C, Wang Y, Luo M, Zhao H, Dong L, Song W, Wang F, Wang W, Zhang J and Yu J: Characterization of microRNA-29 family expression and investigation of their mechanistic roles in gastric cancer. Carcinogenesis 35(2): 497-506, 2014. PMID: 24130168. DOI: 10.1093/carcin/bgt337

113 Ding ZY, Li R, Zhang QJ, Wang Y, Jiang Y, Meng QY, Xi QL and Wu GH: Prognostic role of cyclin D2/D3 in multiple human malignant neoplasms: A systematic review and meta-analysis. Cancer Med 8(6): 2717-2729, 2019. PMID: 30950241. DOI: $10.1002 /$ cam 4.2152

114 Sampieri CL, de la Peña S, Ochoa-Lara M, Zenteno-Cuevas R and León-Córdoba K: Expression of matrix metalloproteinases 2 and 9 in human gastric cancer and superficial gastritis. World $\mathbf{J}$ Gastroenterol 16(12): 1500-1505, 2010. PMID: 20333791. DOI: 10.3748/wjg.v16.i12.1500

115 Wu S, Liu F, Xie L, Peng Y, Lv X, Zhu Y, Zhang Z and He X: miR-125b suppresses proliferation and invasion by targeting MCL1 in gastric cancer. Biomed Res Int 2015: 365273, 2015. PMID: 26504803. DOI: 10.1155/2015/365273

116 Liu Y, Zhang X, Zhang Y, Hu Z, Yang D, Wang C, Guo M and Cai Q: Identification of miRNomes in human stomach and gastric carcinoma reveals miR-133b/a-3p as therapeutic target for gastric cancer. Cancer Lett 369(1): 58-66, 2015. PMID: 26276722. DOI: 10.1016/j.canlet.2015.06.028

117 Lee WS, Kim N, Park YR, Oh HH, Myung E, Kim SH, Yu HM, Kim MY, Oak CY, Chung CY, Park HC, Myung DS, Cho SB and
Joo YE: Myeloid cell leukemia-1 promotes epithelialmesenchymal transition of human gastric cancer cells. Oncol Rep 34(2): 1011-1016, 2015. PMID: 26058661. DOI: 10.3892/or. 2015.4040

118 Lee WS, Park YL, Kim N, Oh HH, Son DJ, Kim MY, Oak CY, Chung CY, Park HC, Kim JS, Myung DS, Cho SB and Joo YE: Myeloid cell leukemia-1 regulates the cell growth and predicts prognosis in gastric cancer. Int J Oncol 46(5): 2154-2162, 2015. PMID: 25672320. DOI: 10.3892/ijo.2015.2890

119 Li M, Wang D, He J, Chen L and Li H: Bcl-X $\mathrm{L}_{\text {: A multifunctional }}$ anti-apoptotic protein. Pharmacol Res 151: 104547, 2020. PMID: 31734345. DOI: $10.1016 /$ j.phrs.2019.104547

$120 \mathrm{Jin} \mathrm{J}, \mathrm{Xiong} \mathrm{Y}$ and Cen B: Bcl-2 and Bcl-xL mediate resistance to receptor tyrosine kinase-targeted therapy in lung and gastric cancer. Anticancer Drugs 28(10): 1141-1149, 2017. PMID: 28885267. DOI: 10.1097/CAD.0000000000000561

121 Zheng X, Dong J, Gong T, Zhang Z, Wang Y, Li Y, Shang Y, Li K, Ren G, Feng B, Li J, Tian Q, Tang S, Sun L, Li M, Zhang H and Fan D: MicroRNA library-based functional screening identified miR-137 as a suppresser of gastric cancer cell proliferation. J Cancer Res Clin Oncol 141(5): 785-795, 2015. PMID: 25342326. DOI: 10.1007/s00432-014-1847-4

122 Wang D, Sun Y, Li W, Ye F, Zhang Y, Guo Y, Zhang DY and Suo J: Antiproliferative effects of the CDK6 inhibitor PD0332991 and its effect on signaling networks in gastric cancer cells. Int J Mol Med 41(5): 2473-2484, 2018. PMID: 29436583. DOI: 10.3892/ ijmm.2018.3460

123 Sherr CJ, Beach D and Shapiro GI: Targeting CDK4 and CDK6: From discovery to therapy. Cancer Discov 6(4): 353-367, 2016. PMID: 26658964. DOI: 10.1158/2159-8290.CD-15-0894

124 O'Leary B, Finn RS and Turner NC: Treating cancer with selective CDK4/6 inhibitors. Nat Rev Clin Oncol 13(7): 417-430, 2016. PMID: 27030077. DOI: 10.1038/nrclinonc.2016.26

125 Jiang K, Xie LF, Xiao TZ, Qiu MY and Wang WL: MiR-181d inhibits cell proliferation and metastasis through PI3K/AKT pathway in gastric cancer. Eur Rev Med Pharmacol Sci 23(20): 8861-8869, 2019. PMID: 31696473. DOI: $10.26355 / \mathrm{eurrev}_{-}$ 201910_19281

126 Sun SC: CYLD: a tumor suppressor deubiquitinase regulating NFkappaB activation and diverse biological processes. Cell Death Differ 17(1): 25-34, 2010. PMID: 19373246. DOI: 10.1038/ cdd.2009.43

127 Ghadami E, Nikbakhsh N, Fattahi S, Kosari-Monfared M, Ranaee M, Taheri H, Amjadi-Moheb F, Godazandeh G, Shafaei S, Nosrati A, Pilehchian Langroudi M, Samadani AA, Amirbozorgi G, Mirnia V and Akhavan-Niaki H: Epigenetic alterations of CYLD promoter modulate its expression in gastric adenocarcinoma: A footprint of infections. J Cell Physiol 234(4): 4115-4124, 2019. PMID: 30132887. DOI: 10.1002/jep.27220

$128 \mathrm{Tu}$ L, Zhao E, Zhao W, Zhang Z, Tang D, Zhang Y, Wang C, Zhuang $\mathrm{C}$ and $\mathrm{Cao} \mathrm{H}$ : hsa-miR-376c-3p regulates gastric tumor growth both in vitro and in vivo. Biomed Res Int 2016: 9604257 , 2016. PMID: 27965982. DOI: 10.1155/2016/9604257

129 Song C, Han Y, Luo H, Qin Z, Chen Z, Liu Y, Lu S, Sun H and Zhou C: HOXA10 induces BCL2 expression, inhibits apoptosis, and promotes cell proliferation in gastric cancer. Cancer Med 8(12): 5651-5661, 2019. PMID: 31364281. DOI: 10.1002/cam4.2440

130 Min KW, Kim DH, Son BK, Kim DH, Kim EK, Seo J, Ahn SB, Jo YJ, Park YS and Ha J: A High Ki67/BCL2 index could predict lower disease-free and overall survival in intestinal-type gastric 
cancer. Eur Surg Res 58(3-4): 158-168, 2017. PMID: 28273657. DOI: $10.1159 / 000448945$

131 Feng C, Xian Q and Liu S: Micro RNA-518 inhibits gastric cancer cell growth by inducing apoptosis via targeting MDM2. Biomed Pharmacother 97: 1595-1602, 2018. PMID: 29793321. DOI: 10.1016/j.biopha.2017.11.091

132 Aboushousha T, Helal N, Hammam O, Ibrahim M, Khaled S, Mostafa A and Anas A: Overview of MDM2 and B-RAF expression in gastric lesions. Open Access Maced J Med Sci 6(10): 1795-1802, 2018. PMID: 30455751. DOI: 10.3889/ oamjms.2018.338

133 Oliner JD, Saiki AY and Caenepeel S: The role of MDM2 amplification and overexpression in tumorigenesis. Cold Spring Harb Perspect Med 6(6): a026336, 2016. PMID: 27194168. DOI: 10.1101/cshperspect.a026336

134 Wang S, Zhao Y, Aguilar A, Bernard D and Yang CY: Targeting the MDM2-p53 protein-Protein interaction for new cancer therapy: Progress and challenges. Cold Spring Harb Perspect Med 7(5): a026245, 2017. PMID: 28270530. DOI: 10.1101/ cshperspect.a026245

135 Jiang M, Shi L, Yang C, Ge Y, Lin L, Fan H, He Y, Zhang D, Miao $Y$ and Yang L: miR-1254 inhibits cell proliferation, migration, and invasion by down-regulating Smurf1 in gastric cancer. Cell Death Dis 10(1): 32, 2019. PMID: 30631050. DOI: $10.1038 / \mathrm{s} 41419-$ 018-1262-x

$136 \mathrm{Fu}$ L, Cui CP, Zhang X and Zhang L: The functions and regulation of Smurfs in cancers. Semin Cancer Biol 67(Pt 2): 102-116, 2020. PMID: 31899247. DOI: 10.1016/j.semcancer.2019.12.023

137 Yang Q, Jie Z, Cao H, Greenlee AR, Yang C, Zou F and Jiang Y: Low-level expression of let-7a in gastric cancer and its involvement in tumorigenesis by targeting RAB40C. Carcinogenesis 32(5): 713-722, 2011. PMID: 21349817. DOI: $10.1093 /$ carcin/bgr035

138 Rodriguez-Gabin AG, Almazan G and Larocca JN: Vesicle transport in oligodendrocytes: probable role of Rab40c protein. J Neurosci Res 76(6): 758-770, 2004. PMID: 15160388. DOI: 10.1002/jnr.20121

$139 \mathrm{Ng}$ EL and Tang BL: Rab GTPases and their roles in brain neurons and glia. Brain Res Rev 58(1): 236-246, 2008. PMID: 18485483. DOI: $10.1016 /$ j.brainresrev.2008.04.006

140 Sahai E and Marshall CJ: RHO-GTPases and cancer. Nat Rev Cancer 2(2): 133-142, 2002. PMID: 12635176. DOI: 10.1038/ $\operatorname{nrc} 725$

141 Ge F, Wang C, Wang W, Liu W and Wu B: MicroRNA-31 inhibits tumor invasion and metastasis by targeting RhoA in human gastric cancer. Oncol Rep 38(2): 1133-1139, 2017. PMID: 28656284. DOI: $10.3892 /$ or.2017.5758

142 Chen Z, Liu S, Xia Y and Wu K: MiR-31 regulates Rho-associated kinase-myosin light chain (ROCK-MLC) pathway and inhibits gastric cancer invasion: Roles of RhoA. Med Sci Monit 22: 46794691, 2016. PMID: 27904131. DOI: 10.12659/msm.898399

143 Liu H, Liu Y, Zhang X and Wang X: Current study of RhoA and associated signaling pathways in gastric cancer. Curr Stem Cell Res Ther 15(7): 607-613, 2020. PMID: 32223738. DOI: 10.2174/1574888X15666200330143958

144 Nam S, Kim JH and Lee DH: RHOA in gastric cancer: Functional roles and therapeutic potential. Front Genet 10: 438, 2019. PMID: 31156701. DOI: $10.3389 /$ fgene.2019.00438

145 Huang T, Zhou Y, Zhang J, Wong CC, Li W, Kwan JSH, Yang R, Chan AKY, Dong Y, Wu F, Zhang B, Cheung AHK, Wu WKK,
Cheng ASL, Yu J, Wong N, Kang W and To KF: SRGAP1, a crucial target of miR-340 and miR-124, functions as a potential oncogene in gastric tumorigenesis. Oncogene 37(9): 1159-1174, 2018. PMID: 29234151. DOI: 10.1038/s41388-017-0029-7

146 Lin R, Cerione RA and Manor D: Specific contributions of the small GTPases Rho, Rac, and Cdc42 to Dbl transformation. J Biol Chem 274(33): 23633-23641, 1999. PMID: 10438546. DOI: $10.1074 / \mathrm{jbc} .274 .33 .23633$

147 Hall A: Rho GTPases and the control of cell behaviour. Biochem Soc Trans 33(Pt 5): 891-895, 2005. PMID: 16246005. DOI: 10.1042/BST20050891

148 Tong M, Jun T, Nie Y, Hao J and Fan D: The role of the Slit/Robo signaling pathway. J Cancer 10(12): 2694-2705, 2019. PMID: 31258778. DOI: $10.7150 /$ jca. 31877

149 Chen Q, Zhang Y and Xu L: microRNA-340 influences cell proliferation, apoptosis and invasion by targeting NF-kB1 in gastric cancer. Int J Clin Exp Pathol 11(7): 3812-3824, 2018. PMID: 31949768

150 Xiao C, Hong H, Yu H, Yuan J, Guo C, Cao H and Li W: MiR340 affects gastric cancer cell proliferation, cycle, and apoptosis through regulating SOCS3/JAK-STAT signaling pathway. Immunopharmacol Immunotoxicol 40(4): 278-283, 2018. PMID: 29658372. DOI: $10.1080 / 08923973.2018 .1455208$

151 Liu F, Hu H, Zhao J, Zhang Z, Ai X, Tang L and Xie L: miR-124$3 p$ acts as a potential marker and suppresses tumor growth in gastric cancer. Biomed Rep 9(2): 147-155, 2018. PMID: 30013778. DOI: 10.3892/br.2018.1113

152 Li X, Jiang M, Chen D, Xu B, Wang R, Chu Y, Wang W, Zhou L, Lei Z, Nie Y, Fan D, Shang Y, Wu K and Liang J: miR-148b-3p inhibits gastric cancer metastasis by inhibiting the Dock6/Rac1/Cdc42 axis. J Exp Clin Cancer Res 37(1): 71, 2018. PMID: 29587866. DOI: 10.1186/s13046-018-0729-Z

153 Gadea G and Blangy A: Dock-family exchange factors in cell migration and disease. Eur J Cell Biol 93(10-12): 466-477, 2014. PMID: 25022758. DOI: 10.1016/j.ejcb.2014.06.003

154 Li Z, Yu X, Wang Y, Shen J, Wu WK, Liang J and Feng F: By downregulating TIAM1 expression, microRNA-329 suppresses gastric cancer invasion and growth. Oncotarget 6(19): 1755917569, 2015. PMID: 25654811. DOI: 10.18632/oncotarget.2755

155 Boissier P and Huynh-Do U: The guanine nucleotide exchange factor Tiam1: a Janus-faced molecule in cellular signaling. Cell Signal 26(3): 483-491, 2014. PMID: 24308970. DOI: 10.1016/j.cellsig.2013.11.034

156 Zhu JM and Yu PW: Effects of Tiam 1 on invasive capacity of gastric cancer cells in vitro and underlying mechanisms. Asian Pac J Cancer Prev 14(1): 201-208, 2013. PMID: 23534724. DOI: 10.7314/apjcp.2013.14.1.201

157 Shi YL, Miao RZ, Cheng L, Guo XB, Yang B, Jing CQ, Zhang L, Jin $X$ and Li LP: Up-regulation of T-lymphoma and metastasis gene 1 in gastric cancer and its involvement in cell invasion and migration. Chin Med J (Engl) 126(4): 640-645, 2013. PMID: 23422181.

158 Vigil D, Cherfils J, Rossman KL and Der CJ: Ras superfamily GEFs and GAPs: validated and tractable targets for cancer therapy? Nat Rev Cancer 10(12): 842-857, 2010. PMID: 21102635. DOI: $10.1038 / \mathrm{nrc} 2960$

159 Wang Z, Yao L, Li Y, Hao B, Wang M, Wang J, Gu W, Zhan H, Liu $\mathrm{G}$ and Wu Q: miR 337 3p inhibits gastric tumor metastasis by targeting ARHGAP10. Mol Med Rep 21(2): 705-719, 2020. PMID: 31789419. DOI: 10.3892/mmr.2019.10856 
160 Bassères DS, Tizzei EV, Duarte AA, Costa FF and Saad ST: ARHGAP10, a novel human gene coding for a potentially cytoskeletal Rho-GTPase activating protein. Biochem Biophys Res Commun 294(3): 579-585, 2002. PMID: 12056806. DOI: 10.1016/S0006-291X(02)00514-4

161 Teng JP, Yang ZY, Zhu YM, Ni D, Zhu ZJ and Li XQ: The roles of ARHGAP10 in the proliferation, migration and invasion of lung cancer cells. Oncol Lett 14(4): 4613-4618, 2017. PMID: 28943961. DOI: 10.3892/ol.2017.6729

162 Liu L, Xie D, Xie H, Huang W, Zhang J, Jin W, Jiang W and Xie D: ARHGAP10 inhibits the proliferation and metastasis of CRC cells via blocking the activity of RhoA/AKT signaling pathway. Onco Targets Ther 12: 11507-11516, 2019. PMID: 31920339. DOI: $10.2147 /$ OTT.S222564

163 Luo N, Guo J, Chen L, Yang W, Qu X and Cheng Z: ARHGAP10, downregulated in ovarian cancer, suppresses tumorigenicity of ovarian cancer cells. Cell Death Dis 7: e2157, 2016. PMID: 27010858. DOI: $10.1038 /$ cddis.2015.401

164 Nadal E, Chen G, Gallegos M, Lin L, Ferrer-Torres D, Truini A, Wang Z, Lin J, Reddy RM, Llatjos R, Escobar I, Moya J, Chang AC, Cardenal F, Capellà G and Beer DG: Epigenetic inactivation of microRNA-34b/c predicts poor disease-free survival in earlystage lung adenocarcinoma. Clin Cancer Res 19(24): 6842-6852, 2013. PMID: 24130071. DOI: 10.1158/1078-0432.CCR-13-0736

165 Lehmann U, Hasemeier B, Christgen M, Müller M, Römermann $\mathrm{D}$, Länger $\mathrm{F}$ and Kreipe $\mathrm{H}$ : Epigenetic inactivation of microRNA gene hsa-mir-9-1 in human breast cancer. J Pathol 214(1): 17-24, 2008. PMID: 17948228 . DOI: $10.1002 /$ path.2251

166 Reddy KB: MicroRNA (miRNA) in cancer. Cancer Cell Int 15: 38, 2015. PMID: 25960691. DOI: 10.1186/s12935-015-0185-1

167 Rakheja D, Chen KS, Liu Y, Shukla AA, Schmid V, Chang TC, Khokhar S, Wickiser JE, Karandikar NJ, Malter JS, Mendell JT and Amatruda JF: Somatic mutations in DROSHA and DICER1 impair microRNA biogenesis through distinct mechanisms in Wilms tumours. Nat Commun 2: 4802, 2014. PMID: 25190313. DOI: $10.1038 /$ ncomms 5802

168 Lodygin D, Tarasov V, Epanchintsev A, Berking C, Knyazeva T, Körner H, Knyazev P, Diebold J and Hermeking H: Inactivation of miR-34a by aberrant CpG methylation in multiple types of cancer. Cell Cycle 7(16): 2591-2600, 2008. PMID: 18719384. DOI: $10.4161 /$ cc.7.16.6533

169 Rupaimoole R and Slack FJ: MicroRNA therapeutics: towards a new era for the management of cancer and other diseases. Nat Rev Drug Discov 16(3): 203-222, 2017. PMID: 28209991. DOI: 10.1038/nrd.2016.246

170 Orellana EA and Kasinski AL: MicroRNAs in cancer: A historical perspective on the path from discovery to therapy. Cancers (Basel) 7(3): 1388-1405, 2015. PMID: 26226002. DOI: 10.3390/ cancers 7030842

171 Taylor MA and Schiemann WP: Therapeutic opportunities for targeting microRNAs in cancer. Mol Cell Ther 2(30): 1-13, 2014. PMID: 25717380. DOI: 10.1186/2052-8426-2-30

172 Gambari R, Brognara E, Spandidos DA and Fabbri E: Targeting oncomiRNAs and mimicking tumor suppressor miRNAs: New trends in the development of miRNA therapeutic strategies in oncology (Review). Int J Oncol 49(1): 5-32, 2016. PMID: 27175518. DOI: $10.3892 /$ ijo.2016.3503

173 Michelfelder S and Trepel M: Adeno-associated viral vectors and their redirection to cell-type specific receptors. Adv Genet 67: 2960, 2009. PMID: 19914449. DOI: 10.1016/S0065-2660(09)67002-4
174 Garzon R, Marcucci G and Croce CM: Targeting microRNAs in cancer: rationale, strategies and challenges. Nat Rev Drug Discov 9(10): 775-789, 2010. PMID: 20885409. DOI: 10.1038/nrd3179

175 Esquela-Kerscher A, Trang P, Wiggins JF, Patrawala L, Cheng A, Ford L, Weidhaas JB, Brown D, Bader AG and Slack FJ: The let7 microRNA reduces tumor growth in mouse models of lung cancer. Cell Cycle 7(6): 759-764, 2008. PMID: 18344688. DOI: $10.4161 / \mathrm{cc} .7 .6 .5834$

$176 \mathrm{Wu}$ Y, Crawford M, Mao Y, Lee RJ, Davis IC, Elton TS, Lee LJ and Nana-Sinkam SP: Therapeutic delivery of MicroRNA-29b by cationic lipoplexes for lung cancer. Mol Ther Nucleic Acids 2: e84, 2013. PMID: 23591808. DOI: 10.1038/mtna.2013.14

177 Wu X, Liu T, Fang O, Dong W, Zhang F, Leach L, Hu X and Luo Z: MicroRNA-708-5p acts as a therapeutic agent against metastatic lung cancer. Oncotarget 7(3): 2417-2432, 2016. PMID: 26678031. DOI: 10.18632/oncotarget.6594

178 Labatut AE and Mattheolabakis G: Non-viral based miR delivery and recent developments. Eur J Pharm Biopharm 128: 82-90, 2018. PMID: 29679644. DOI: 10.1016/j.ejpb.2018.04.018

179 Zhang L, Liao Y and Tang L: MicroRNA-34 family: a potential tumor suppressor and therapeutic candidate in cancer. J Exp Clin Cancer Res 38(1): 53, 2019. PMID: 30717802. DOI: 10.1186/ s13046-019-1059-5

180 Reid G, Johnson TG and van Zandwijk N: Manipulating microRNAs for the Treatment of Malignant Pleural Mesothelioma: Past, Present and Future. Front Oncol 10: 105, 2020. PMID: 32117755. DOI: 10.3389/fonc.2020.00105

181 Zhang L, Liao Y and Tang L: MicroRNA-34 family: a potential tumor suppressor and therapeutic candidate in cancer. J Exp Clin Cancer Res 38(1): 53, 2019. PMID: 30717802. DOI: 10.1186/ s13046-019-1059-5

182 Jones D: Setbacks shadow microRNA therapies in the clinic. Nat Biotechnol 36(10): 909-910, 2018. PMID: 30307922. DOI: 10.1038/nbt1018-909

183 van Zandwijk N, Pavlakis N, Kao SC, Linton A, Boyer MJ, Clarke S, Huynh Y, Chrzanowska A, Fulham MJ, Bailey DL, Cooper WA, Kritharides L, Ridley L, Pattison ST, MacDiarmid J, Brahmbhatt $\mathrm{H}$ and Reid G: Safety and activity of microRNA-loaded minicells in patients with recurrent malignant pleural mesothelioma: a firstin-man, phase 1, open-label, dose-escalation study. Lancet Oncol 18(10): 1386-1396, 2017. PMID: 28870611. DOI: 10.1016/ S1470-2045(17)30621-6

184 Reid G, Kao SC, Pavlakis N, Brahmbhatt H, MacDiarmid J, Clarke S, Boyer M and van Zandwijk N: Clinical development of TargomiRs, a miRNA mimic-based treatment for patients with recurrent thoracic cancer. Epigenomics 8(8): 1079-1085, 2016. PMID: 27185582. DOI: $10.2217 / \mathrm{epi}-2016-0035$

185 MacLeod AR and Crooke ST: RNA therapeutics in oncology: Advances, challenges, and future directions. J Clin Pharmacol 57 Suppl 10: S43-S59, 2017. PMID: 28921648. DOI: 10.1002/ jcph.957

$186 \mathrm{Li} \mathrm{Z}$ and Rana TM: Therapeutic targeting of microRNAs: current status and future challenges. Nat Rev Drug Discov 13(8): 622638, 2014. PMID: 25011539. DOI: 10.1038/nrd4359

187 Garofalo M, Leva GD and Croce CM: MicroRNAs as anti-cancer therapy. Curr Pharm Des 20(33): 5328-5335, 2014. PMID: 24479801. DOI: $10.2174 / 1381612820666140128211346$

188 Malek A, Merkel O, Fink L, Czubayko F, Kissel T and Aigner A: In vivo pharmacokinetics, tissue distribution and underlying mechanisms of various PEI(-PEG)/siRNA complexes. Toxicol 
Appl Pharmacol 236(1): 97-108, 2009. PMID: 19371615. DOI: 10.1016/j.taap.2009.01.014

189 Wang AZ, Langer R and Farokhzad OC: Nanoparticle delivery of cancer drugs. Annu Rev Med 63: 185-198, 2012. PMID: 21888516. DOI: 10.1146/annurev-med-040210-162544

190 Rozema DB, Lewis DL, Wakefield DH, Wong SC, Klein JJ, Roesch PL, Bertin SL, Reppen TW, Chu Q, Blokhin AV, Hagstrom JE and Wolff JA: Dynamic PolyConjugates for targeted in vivo delivery of siRNA to hepatocytes. Proc Natl Acad Sci U.S.A. 104(32): 12982-12987, 2007. PMID: 17652171. DOI: 10.1073/ pnas.0703778104

191 Copolovici DM, Langel K, Eriste E and Langel Ü: Cellpenetrating peptides: design, synthesis, and applications. ACS Nano 8(3): 1972-1994, 2014. PMID: 24559246. DOI: 10.1021/ nn4057269

192 Thorén PE, Persson D, Isakson P, Goksör M, Onfelt A and Nordén B: Uptake of analogs of penetratin, Tat(48-60) and oligoarginine in live cells. Biochem Biophys Res Commun 307(1): 100-107, 2003. PMID: 12849987. DOI: 10.1016/s0006-291x(03)01135-5

193 Darnell JE Jr: Transcription factors as targets for cancer therapy. Nat Rev Cancer 2(10): 740-749, 2002. PMID: 12360277 . DOI: $10.1038 / \mathrm{nrc} 906$

194 Bushweller JH: Targeting transcription factors in cancer - from undruggable to reality. Nat Rev Cancer 19(11): 611-624, 2019. PMID: 31511663. DOI: 10.1038/s41568-019-0196-7
195 Mott HR and Owen D: Bioblockades join the assault on small G protein signalling. Semin Cancer Biol 54: 149-161, 2019. PMID: 29307570. DOI: 10.1016/j.semcancer.2018.01.001

196 Fletcher S: MCL-1 inhibitors - where are we now (2019)? Expert Opin Ther Pat 29(11): 909-919, 2019. PMID: 31566022. DOI: $10.1080 / 13543776.2019 .1672661$

197 Rusiecki R, Witkowski J and Jaszczewska-Adamczak J: MDM2p53 interaction inhibitors: The current state-of-art and updated patent review (2010-present). Recent Pat Anticancer Drug Discov 14(4): 324-369, 2019. PMID: 31642413. DOI: 10.2174/ 1574892814666191022163540

198 Zanjirband M and Rahgozar S: Targeting p53-MDM2 interaction using small molecule inhibitors and the challenges needed to be addressed. Curr Drug Targets 20(11): 1091-1111, 2019. PMID: 30947669. DOI: $10.2174 / 1389450120666190402120701$

Received June 22, 2021

Revised July 29, 2021

Accepted July 30, 2021 